\title{
PACAP/Receptor System in Urinary Bladder Dysfunction and Pelvic Pain Following Urinary Bladder Inflammation or Stress
}

\author{
Beatrice M. Girard, Katharine Tooke and Margaret A. Vizzard* \\ Department of Neurological Sciences, Larner College of Medicine, The University of Vermont, Burlington, VT, United States
}

\section{OPEN ACCESS}

Edited by:

Anna P. Malykhina,

University of Colorado Denver School of Medicine, United States

Reviewed by:

Janet R. Keast,

University of Melbourne, Australia

E. Michelle Southard-Smith, Vanderbilt University Medical Center, United States

John Mathai,

Beth Israel Deaconess Medical Center, Harvard Medical School,

United States

Changfeng Tai,

University of Pittsburgh, United States

${ }^{*}$ Correspondence:

Margaret A. Vizzard

margaret.vizzard@uvm.edu

Received: 22 August 2017 Accepted: 16 November 2017 Published: 04 December 2017

Citation:

Girard BM, Tooke $K$ and Vizzard MA (2017) PACAP/Receptor System in Urinary Bladder Dysfunction and Pelvic Pain Following Urinary

Bladder Inflammation or Stress.

Front. Syst. Neurosci. 11:90. doi: 10.3389/fnsys.2017.00090
Complex organization of CNS and PNS pathways is necessary for the coordinated and reciprocal functions of the urinary bladder, urethra and urethral sphincters. Injury, inflammation, psychogenic stress or diseases that affect these nerve pathways and target organs can produce lower urinary tract (LUT) dysfunction. Numerous neuropeptide/receptor systems are expressed in the neural pathways of the LUT and non-neural components of the LUT (e.g., urothelium) also express peptides. One such neuropeptide receptor system, pituitary adenylate cyclase-activating polypeptide (PACAP; Adcyap1) and its cognate receptor, PAC1 (Adcyap1r1), have tissue-specific distributions in the LUT. Mice with a genetic deletion of PACAP exhibit bladder dysfunction and altered somatic sensation. PACAP and associated receptors are expressed in the LUT and exhibit neuroplastic changes with neural injury, inflammation, and diseases of the LUT as well as psychogenic stress. Blockade of the PACAP/PAC1 receptor system reduces voiding frequency in preclinical animal models and transgenic mouse models that mirror some clinical symptoms of bladder dysfunction. A change in the balance of the expression and resulting function of the PACAP/receptor system in CNS and PNS bladder reflex pathways may underlie LUT dysfunction including symptoms of urinary urgency, increased voiding frequency, and visceral pain. The PACAP/receptor system in micturition pathways may represent a potential target for therapeutic intervention to reduce LUT dysfunction.

Keywords: micturition, neuropeptides, inflammation, psychogenic stress, NGF, cyclophosphamide, PAC1, PACAP(6-38)

Abbreviations: AC, adenylate cyclase; ATP, adenosine triphosphate; B1, bradykinin receptor B1; B2, bradykinin receptor B2. $\mathrm{BAC}$, bacterial artificial chromosome; BDNF, brain-derived neurotrophic factor; BNST, bed nucleus of the stria terminalis; BOO, bladder outlet obstruction; cAMP, cyclic adenosine monophosphate; CGRP, calcitonin gene-related peptide; CNS, central nervous system; CRH, corticotropin releasing hormone; CYP, cyclophosphamide; DH, dorsal horn; DRG, dorsal root ganglia; FIC, feline interstitial cystitis; FKBP5, FK506-binding protein 5; HPA, hypothalamic-pituitary-adrenal; IR, immunoreactivity; LCP, lateral collateral pathway; LUT, lower urinary tract; MPG, major pelvic ganglia; mRNA, messenger ribonucleic acid; NGF, nerve growth factor; NGF-OE, nerve growth factor overexpression; NO, nitric oxide; $\mathrm{OAB}$, overactive bladder; P2X and P2Y, purinergic receptors; $\mathrm{p}^{\text {NTR }}{ }^{\text {, }} 75$ neurotrophin receptor; PAC1, PACAP receptor 1; PACAP, pituitary adenylate cyclase-activating polypeptide; PACAP-EGFP, PACAP-enhanced green fluorescent protein; PAG, periaqueductal gray; PBS/IC, painful bladder syndrome/interstitial cystitis; PC, pheochromocytoma; PCR, polymerase chain reaction; PLC, phospholipase C; PMC, pontine micturition center; PNS, peripheral nervous system; PTSD, post-traumatic stress disorder; RVS, repeated variate stress; SCI, spinal cord injury; SP, substance P; SPN, sacral parasympathetic nucleus; TrkA, tropomyosin receptor kinase $\mathrm{A}$; TrkB, tropomyosin receptor kinase $\mathrm{B}$; TRPA1, transient receptor potential ankyrin 1; TRPM8, transient receptor potential melastatin 8; TRPV1, transient receptor potential vanilloid 1; TRPV2, transient receptor potential vanilloid 2; TRPV4, transient receptor potential vanilloid 4; VIP, vasoactive intestinal polypeptide; VPAC1, VIP receptor 1; VPAC2, VIP receptor 2; WAS, water avoidance stress; WT, wildtype. 


\section{INTRODUCTION}

Micturition, the expulsion of urine from the urinary bladder through the urethra, is an important part of everyday life. Micturition is a basic physiological function to which we give little thought until this daily behavior is changed in some way. Normal micturition involves the filling and storage of urine in the bladder, and the periodic voiding of urine at socially appropriate times. Storage and elimination functions involve the reciprocal functions of the bladder, urethra and external urethral sphincter (i.e., urethral rhabdosphincter). These two modes of operation are controlled by the coordination of the structural features of the bladder and complex neural pathways organized in the CNS and PNS (Elbadawi, 1996; Andersson, 2004).

\section{ANATOMY OF THE LOWER URINARY TRACT (LUT)}

The LUT consists of the urinary bladder and urethra. The urethra is composed of both smooth and striated muscle (Andersson, 2004). The urinary bladder is a hollow, smooth muscle organ and consists of two main parts, the bladder body and the bladder base (Elbadawi, 1996; Andersson, 2004). The bladder body is located above the opening of the urethra. The base contains the trigone, urethrovesical junction, and the anterior bladder wall (Elbadawi, 1996; Andersson, 2004). The urinary bladder wall is organized into layers: mucosa, muscle, and serosa and adventitia (Tank, 2009). The mucosal layer consists of transitional epithelial cells that line the lumen of the bladder and a lamina propria beneath the basement membrane of the epithelial cells (Tank, 2009). The urothelium, a layer of epithelial cells, lines the lumen of the bladder. The lamina propria is composed of a thick layer of cells (e.g., fibroblasts, adipocytes, interstitial cells, and afferent and efferent nerve terminals), collagen, elastic fibers and blood vessels (Andersson and McCloskey, 2014). The muscular layer is composed of smooth muscle cells that constitute the muscular wall of the bladder. It is structurally different from the smooth muscle of the trigone and urethra because it consists of an inner and outer longitudinal layer and a middle circular layer of smooth muscle (Andersson, 2004). These muscle cells relax and elongate during bladder filling, whereas the urethra is closed and non-compliant. Bladder emptying involves the coordinated contraction of the detrusor muscle as well as relaxation, opening, and dilation of the urethra (Elbadawi, 1996; Andersson, 2004). The serosal layer surrounds the superior and lateral external surfaces of the bladder wall, whereas loose connective tissue, the adventitia, surrounds the retroperitoneal bladder wall (Tank, 2009).

\section{UROTHELIUM}

The urothelium is a layer of transitional epithelium capable of detecting diverse stimuli including, mechanical, chemical, and thermal stimuli. The urothelium is composed of three layers: an innermost basal cell layer attached to a basement membrane, an intermediate layer, and a superficial apical layer (Birder, 2005; Apodaca et al., 2007; Birder and de Groat, 2007; Birder et al., 2009, 2014; Birder and Andersson, 2013). The apical layer contains large, hexagonal shaped umbrella cells that change shape during filling to expand the epithelial surface giving the transitional epithelium its name. The apical layer also acts as a barrier against substances in the urine that may be detrimental to the bladder. This barrier function can be compromised during injury or inflammation, allowing toxic substances to reach the suburothelial nerve plexus and muscular layers, contributing to urinary urgency, frequency, and pain during voiding (Birder, 2005; Apodaca et al., 2007; Birder and de Groat, 2007; Birder et al., 2009, 2014; Birder and Andersson, 2013).

The urothelium, once thought to act only as a passive barrier, is now appreciated to play important and active roles in afferent signaling. This active function involves receiving afferent nerve input from nearby nerves in the suburothelial nerve plexus and in response, communicating directly with the nerves that innervate the bladder, the smooth muscle of the bladder and local inflammatory cells (Birder, 2005; Apodaca et al., 2007; Birder and de Groat, 2007; Birder et al., 2009, 2014; Birder and Andersson, 2013). The apical layer of the urothelium expresses surface receptors and ion channels (Birder, 2005; Birder and de Groat, 2007; Birder and Andersson, 2013; Merrill et al., 2016) enabling the recognition of diverse sensory stimuli. Receptors found in the urothelium are numerous and diverse and include: $\mathrm{B} 1$ and $\mathrm{B} 2$ bradykinin receptors activated by bradykinin (Chopra et al., 2005; Birder and de Groat, 2007), p75 ${ }^{N T R}$, TrkA, and TrkB activated by neurotrophins (e.g., NGF, BDNF) (Qiao and Vizzard, 2002b; Murray et al., 2004; Petruska and Mendell, 2004; Merrill et al., 2016), purinergic receptors (P2X and P2Y) activated by ATP (Cockayne et al., 2005; Wang et al., 2005; Ford and Cockayne, 2011; Birder and Andersson, 2013), adrenergic receptors activated by norepinephrine (Birder and Andersson, 2013), cholinergic receptors activated by acetylcholine (Beckel et al., 2006; Birder and Andersson, 2013), neuropeptide receptors including PACAP type 1 receptor $(\mathrm{PAC} 1)$ and VIP receptor 2 (VPAC2) (Arms and Vizzard, 2011; Merrill et al., 2013a; Gonzalez et al., 2014b). Transient receptor potential (TRP) channels, activated by inflammatory mediators, temperature changes and/or $\mathrm{pH}$ changes within the bladder (Birder and Andersson, 2013; Merrill et al., 2016), are also expressed by the urothelium, including members of the vanilloid (V), melastatin (M), and ankyrin (A) families: TRPV1, TRPV2, TRPV4, TRPM8, and TRPA1 (Skryma et al., 2011; Merrill et al., 2012; Avelino et al., 2013; Gonzalez et al., 2014b). In addition, recent studies demonstrate the presence of another cell type in the rat urethra that recognizes and responds to diverse stimuli. Cholinergic chemosensory cells are found in the rat urethra in close proximity to sensory nerve fibers expressing nicotinic acetylcholine (ACh) receptors (Deckmann et al., 2014). These cells respond to bitter (denatonium), umami (monosodium glutamate) and uropathogenic Escherichia coli stimulation and intraurethral denatonium increases detrusor activity (Deckmann et al., 2014). It is suggested that these chemosensory cells in the rat urethra may monitor for the presence of hazardous compounds, release ACh and affect bladder function (Deckmann et al., 2014). 
Following stimulation, the urothelium can release signaling mediators to produce localized vascular changes (Birder and de Groat, 2007; Fowler et al., 2008) and to influence adjacent tissues and cells, including: detrusor smooth muscle, afferent nerve fibers in the suburothelial nerve plexus, inflammatory cells and interstitial cells within the bladder (Birder and de Groat, 2007; Fowler et al., 2008; Birder and Andersson, 2013; Merrill et al., 2016). For example, the urothelium can release many signaling molecules, including, ATP, (Ferguson et al., 1997; Birder and Andersson, 2013), NO (Birder and Andersson, 2013), acetylcholine (Birder and de Groat, 2007), substance P, cytokines, chemokines and prostaglandins as well as a variety of neurotrophic factors (Arms and Vizzard, 2011; Merrill et al., 2013a; Gonzalez et al., 2014a,b; Merrill et al., 2016). The release of signaling molecules from the urothelium can be altered with injury, inflammation and disease (Birder, 2005; Birder and de Groat, 2007; Arms and Vizzard, 2011; Birder and Andersson, 2013; Merrill et al., 2013a, 2016; Gonzalez et al., 2014a,b).

\section{NEURAL CONTROL OF MICTURITION}

The LUT has two phases of operation (storage and elimination), that are under CNS and voluntary control (Fowler et al., 2008; Griffiths, 2015; Miyazato et al., 2017) (Figure 1). During the filling phase, the detrusor smooth muscle is relaxed and the urethral sphincter is contracted. In the emptying phase, the opposite occurs (Fowler et al., 2008; Griffiths, 2015; Miyazato et al., 2017). These processes are controlled by both the autonomic (sympathetic and parasympathetic) and the somatic nervous system (Figure 1A).

The cell bodies of the preganglionic sympathetic innervation to the urogenital organs are located in the intermediolateral gray matter of the lower thoracic and upper lumbar spinal cord (T10-L2) (de Groat, 1990, 1993; Elbadawi, 1996; Holstege, 2005; Fowler et al., 2008). After projecting from the spinal cord, these cells form lumbar splanchnic nerves and synapse in the inferior mesenteric ganglion. Postganglionic sympathetic fibers then travel from the ganglion to urogenital organs through the pelvic and hypogastric nerves (de Groat, 1990, 1993; Elbadawi, 1996; Holstege, 2005; Fowler et al., 2008) (Figure 1C). These sympathetic fibers act either directly on the bladder or indirectly via connections with vesical or pelvic ganglia (de Groat, 1990, 1993; Elbadawi, 1996; Holstege, 2005; Fowler et al., 2008). The sympathetic system is activated alone during bladder filling, and acts to inhibit the detrusor muscle causing relaxation and to excite the bladder neck and urethra causing contraction (de Groat, 1990, 1993; Elbadawi, 1996; Holstege, 2005; Fowler et al., 2008) (Figure 1C). However, the contribution of the sympathetic system to continence across species is debatable. For example, in humans and cats, sympathetic innervation of the detrusor may contribute to continence (Vaughan and Satchell, 1992; Khadra et al., 1995; Andersson and Arner, 2004) by modulating transmission in parasympathetic ganglion neurons (De Groat and Saum, 1972), but this is less clear in rodents (Keast et al., 2015). There is limited evidence that sympathetic noradrenergic pelvic ganglion neurons innervate the

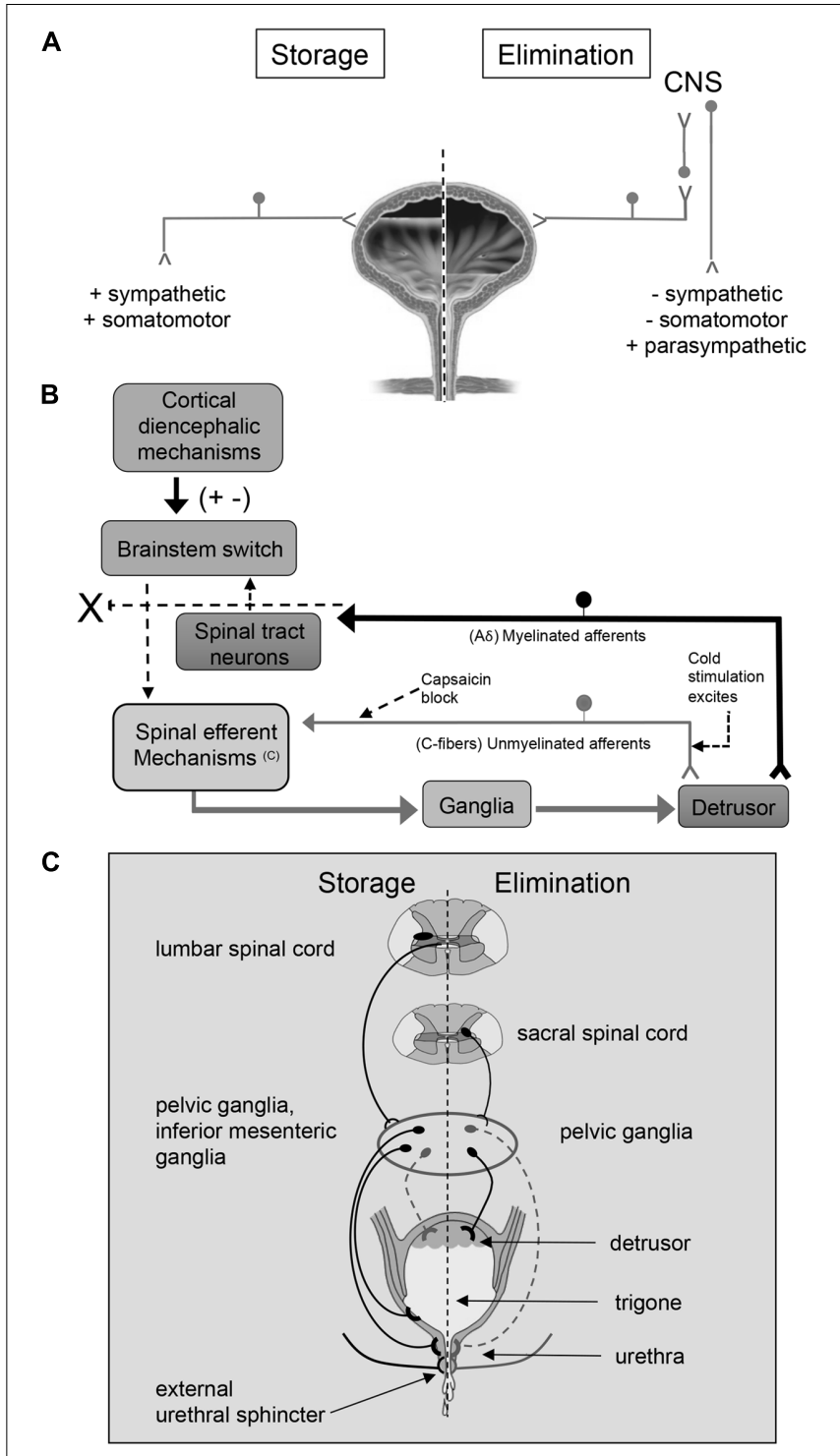

FIGURE 1 | An overview of micturition reflex control. Neural control of lower urinary tract function (A) involves the coordinated activity of afferent (B) and efferent pathways (C). (B) Micturition is initiated by a supraspinal reflex pathway that passes through a center in the brainstem [figure from (Fowler et al., 2008) with permission]. The pathway is triggered by myelinated afferents (A $\delta$-fibers), which are connected to the mechanoreceptors in the bladder wall. Suprasacral spinal cord injury interrupts the connections between the brain and spinal cord and initially causing the micturition reflex to be areflexic. Following $\mathrm{SCl}$, a spinal micturition reflex emerges that is now triggered by unmyelinated bladder afferents (C-fibers). The $\mathrm{C}$-fiber reflex pathway is usually weak or undetectable in spinal cord intact animals. Cold water stimulation of the $\mathrm{C}$-fiber bladder afferents activates voiding responses in patients with SCl. The C-fiber neurotoxin, capsaicin (20-30 mg subcutaneously), blocks the C-fiber reflex in cats with $\mathrm{SCl}$ but does not block micturition reflexes in spinal intact cats. Intravesical capsaicin also suppresses detrusor hyperreflexia and cold-evoked reflexes in patients with neurogenic bladder dysfunction (Fowler et al., 2008). This schematic is based on results from electrophysiological studies in cats (de Groat and Yoshimura, 2006). Additional species differences in afferent control mechanisms of micturition reflexes are described in the text. (C) Excitatory (black) and inhibitory (gray) nerves activated during storage and elimination (voiding) are shown.

(Continued) 


\begin{abstract}
FIGURE 1 | Continued
External urethral sphincter (i.e., urethral rhabdosphincter) innervation via pudendal nerves is also indicated. Broken lines indicate neuronal pathways that are less well understood. Storage reflexes, activated during bladder filling, are organized primarily in the spinal cord, whereas voiding is mediated by reflex mechanisms organized in the brain. During bladder filling and storage, the sympathetic nervous system plays a major role. Preganglionic neurons in the rostral lumbar spinal cord excite sympathetic neurons in the inferior mesenteric ganglia and pelvic ganglia causing contraction of smooth muscle in the trigone and urethra, and this is coordinated with contraction of the external urethral sphincter. During bladder filling and storage, the sympathetic nervous system acts to inhibit the detrusor muscle causing relaxation and to excite the bladder neck and urethra causing contraction, preventing incontinence. However, the contribution of the sympathetic system to continence across species is debatable (broken lines). See text for additional details. During bladder filling, the parasympathetic efferent pathway to the bladder, including a population of CNS (e.g., pontine micturition center) neurons, is turned off. When a threshold level of bladder distension is reached during filling, the afferent activity from bladder mechanoreceptors switches the pathway from the storage to the elimination mode. The parasympathetic nervous system predominates during elimination (voiding). Activation of sacral preganglionic neurons excites parasympathetic ganglion neurons in the pelvic ganglia. During elimination, the activity of the parasympathetic nervous system results in urinary bladder contraction, whereas sympathetic activity and somatomotor activity is withdrawn. Figure adapted from (de Groat, 1990, 1993; de Groat et al., 1998; de Groat and Araki, 1999; Middleton and Keast, 2004; Vizzard, 2006; de Groat and Yoshimura, 2012; de Groat and Wickens, 2013; Merrill et al., 2016).
\end{abstract}

bladder, which parallels the observation of sparse sympathetic noradrenergic innervation of the detrusor in rodents (Andersson and Wein, 2004; Forrest et al., 2014).

The cell bodies of the preganglionic parasympathetic nerves that innervate the bladder are located in the lateral horn of sacral spinal cord (S2-S4). These fibers project from the spinal cord in ventral roots and immediately separate as pelvic splanchnic nerves (i.e., pelvic nerve). The pelvic nerve synapses on terminal ganglia (e.g., intramural ganglia, MPG) and innervates the urogenital organs (de Groat, 1990, 1993; Elbadawi, 1996; Holstege, 2005; Fowler et al., 2008) (Figure 1C). The parasympathetic system is activated alone during voiding, and acts to excite and contract the detrusor muscle (de Groat, 1990, 1993; Elbadawi, 1996; Holstege, 2005; Fowler et al., 2008) (Figure 1C). The urethral sphincter is relaxed during voiding due to the release of sympathetic activation.

The external urethral sphincter muscle is made up of striated muscle and is controlled by the somatic nervous system. The somatic motor neurons that innervate this structure have cell bodies located in the ventrolateral part of the ventral horn of the upper sacral spinal cord (S2-S4) in a nucleus called Onuf's nucleus or the dorsolateral nucleus, depending on species (de Groat, 1990, 1993; Elbadawi, 1996; Holstege, 2005; Fowler et al., 2008). These motor neurons reach the external urethral sphincter (i.e., urethral rhabdosphincter) via the pudendal nerve.

The PMC, also called Barrington's nucleus, is located in the dorsolateral pontine tegmentum of the brainstem and controls the function of the urinary bladder as well as other pelvic organs (Rouzade-Dominguez et al., 2003). Neurons in the PMC send direct excitatory projections to preganglionic neurons in the sacral spinal cord (de Groat, 1990, 1993; Elbadawi, 1996;
Holstege and Mouton, 2003; Holstege, 2005; Fowler et al., 2008; Beckel and Holstege, 2011; Hou et al., 2016). Stimulation of the PMC leads to contraction of the detrusor smooth muscle and micturition (Hou et al., 2016). The PMC not only augments parasympathetic outflow but also attenuates output of preganglionic sympathetic and motor neurons in Onuf's nucleus resulting in bladder contraction and sphincter relaxation (de Groat, 1990, 1993; Elbadawi, 1996; Holstege and Mouton, 2003; Holstege, 2005; Fowler et al., 2008; Beckel and Holstege, 2011). Afferent projections carrying information about bladder filling is first processed in the PAGmatter in the brainstem before being relayed to the PMC (de Groat, 1990, 1993; Elbadawi, 1996; Holstege and Mouton, 2003; Holstege, 2005; Fowler et al., 2008; Beckel and Holstege, 2011).

The micturition reflex switches the bladder from the filling phase to the emptying phase. During the filling phase, the sympathetic nervous system inhibits the detrusor smooth muscle, allowing the bladder to increase in size. In addition, the urethral sphincter contracts under background stimulation by the sympathetic nervous system maintaining continence (Holstege, 2005; Fowler et al., 2008; Beckel and Holstege, 2011). When the detrusor is relaxed, the bladder base is flat, and the urethra is pulled upward, constricting its orifice and further impeding the flow of urine. The switch to the emptying phase is triggered by tension in the urinary bladder during filling that stimulates stretch receptors (slowly adapting mechanoreceptors) within the bladder wall (Holstege, 2005; Fowler et al., 2008). These receptors activate $\mathrm{A} \delta$ - and $\mathrm{C}$-fibers that convey sensory information about bladder distention and noxious stimuli, respectively, from the bladder neck and urethra to the lumbosacral spinal cord (L4S4) via the pelvic, pudendal and hypogastric nerves (Holstege and Mouton, 2003; Holstege, 2005; Fowler et al., 2008; Beckel and Holstege, 2011). A $\delta$ - and C-fibers enter the spinal cord through Lissauer's tract and synapse in spinal cord laminae (i.e., I, V, VII, X) that contain preganglionic parasympathetic neurons as well as projection neurons that send axons to the PAG (Holstege and Mouton, 2003; Holstege, 2005; Fowler et al., 2008; Beckel and Holstege, 2011). Signals then travel from the PAG to the PMC and back to the lumbosacral spinal cord to synapse on preganglionic sympathetic and parasympathetic neurons (Holstege and Mouton, 2003; Holstege, 2005; Fowler et al., 2008; Beckel and Holstege, 2011). The PMC inhibits the preganglionic sympathetic control that releases the contraction of the sphincter and withdraws the inhibition of the detrusor. A few seconds later, there is an increase in the activity of the parasympathetic system, contracting the detrusor smooth muscle. The micturition reflex is a spinobulbospinal reflex because information travels from the spinal cord to the brainstem and back to the spinal cord to convey information regarding bladder filling (Holstege and Mouton, 2003; Holstege, 2005; Fowler et al., 2008; Beckel and Holstege, 2011).

The micturition reflex occurs without conscious control only in infants. In adults, voluntary control via higher brain centers can override the micturition reflex. This is necessary in humans for social purposes, and in animals for survival mechanisms, such as the marking of territory (de Groat et al., 1998; de Groat and Araki, 1999). Therefore, CNS control of the micturition reflex 
from supraspinal levels is necessary. As mentioned previously, integration occurs between the descending and ascending signals of the micturition reflex in the PAG. Several higher brain centers project to the PAG, including the hypothalamus, preoptic region, central nucleus of the amygdala, BNST, and prefrontal cortex (Beckel and Holstege, 2011). During filling, these higher brain centers can prevent the PAG from exciting neurons in the PMC and prevent voiding or incontinence (Holstege and Mouton, 2003; Holstege, 2005; Fowler et al., 2008; Beckel and Holstege, 2011).

In addition to efferent functions, the pelvic nerve contains two types of afferent fibers: C-fibers and A $\delta$-fibers. A $\delta$-fibers are myelinated fibers that transmit information to the brain about the degree of bladder distension and are essential for the generation of storage and elimination reflexes (Janig and Morrison, 1986). In contrast to the reflex underlying the storage phase, the elimination reflex relies on supraspinal circuitry as demonstrated by voiding dysfunction following suprasacral SCI (Gonzalez et al., 2014a) (Figure 1B). C-fibers are unmyelinated fibers that are insensitive to bladder filling under normal conditions (Gonzalez et al., 2014a). In humans, C-fibers only respond when a noxious stimulus, such as chemical irritation, is present (Fowler et al., 2008). The C-fiber reflex pathway is usually weak or undetectable in animals with an intact nervous system. Stimulation of the C-fiber bladder afferents by installation of ice water into the bladder (cold stimulation) activates voiding responses in patients with SCI (Fowler et al., 2008) (Figure 1B). Subcutaneous capsaicin administration blocks the C-fiber reflex in cats with SCI but does not block micturition reflexes in spinal intact cats (Fowler et al., 2008) (Figure 1B). Intravesical capsaicin also suppresses detrusor hyperreflexia and cold-evoked reflexes in patients with neurogenic bladder dysfunction (Fowler et al., 2008) (Figure 1B). In cats, the recovery of bladder function after a suprasacral SCI is mediated by a change in the afferent limb of the micturition reflex pathway and synaptic plasticity in the spinal cord (de Groat et al., 1981; Fowler et al., 2008; de Groat and Yoshimura, 2010). Following chronic SCI in cats, unmyelinated C-fiber afferents, rather than A $\delta$ afferents, initiate voiding and a spinal micturition reflex (de Groat and Yoshimura, 2010) (Figure 1B). The situation in rats following SCI is more complex. In spinal intact rats and those with chronic SCI, A $\delta$ afferents initiate the micturition reflex (Mallory et al., 1989). Although it has been demonstrated that C-fibers are not necessary for spinal micturition reflexes after SCI in rats, C-fibers do contribute to the appearance of non-voiding contractions and detrusor sphincter dyssynergia in deeply anesthetized rats with SCI (Cheng and de Groat, 2004).

Bladder afferent fibers in the pelvic nerve in rodents travel through the dorsal roots into the lateral dorsal root entry zone (i.e., Lissauer's tract) and then give off axon collaterals that extend ventromedially and ventrolaterally along the superficial laminae of the DH. Bladder afferent fibers project to the dorsal commissure and to the SPN (laminae V-VII) that contains preganglionic parasympathetic neurons (Donovan et al., 1983; Noto et al., 1991; Steers et al., 1991; de Groat, 1993; Nadelhaft and Vera, 1995; Marson, 1997; Arms and Vizzard, 2011; Beckel and Holstege, 2011; de Groat and Yoshimura, 2012; de Groat and
Wickens, 2013; Merrill et al., 2016). The ventrolateral pathway that projects along the lateral edge of the $\mathrm{DH}$ is referred to as the LCP of Lissauer's tract (Morgan et al., 1981; Morgan, 1990). The medial collateral pathway, composed of afferent projections from the pudendal nerve and genital structures, projects into the dorsal commissure region (Morgan et al., 1981; Kawatani et al., 1990; Morgan, 1990).

Many bladder afferent fibers project to the SPN, synapsing with preganglionic parasympathetic neurons (Morgan et al., 1981; Morgan, 1990; Fowler et al., 2008), as well as to the dorsal commissure and superficial DH (Morgan et al., 1981; Fowler et al., 2008). The lumbosacral dorsal commissure, superficial DH, and SPN all contain interneurons important to urinary bladder function (de Groat, 1993; Fowler et al., 2008) that contribute to local circuit function as well as to supraspinal circuitry (Fowler et al., 2008). Some bladder afferents synapse with ascending pathways in the spinal cord projecting to supraspinal regions including the PAG and PMC (de Groat, 1993; Fowler et al., 2008).

There continues to be tremendous interest in growth factors (e.g., NGF, BDNF) and associated receptors (e.g., TrkA, TrkB, $\mathrm{p} 75^{N T R}$ ) and the roles they play the regulation of micturition in health and disease as well as their biomarker potential for LUT disease (Dmitrieva and McMahon, 1996; McMahon, 1996; Clemow et al., 1998; Mendell et al., 1999; Vizzard, 2000b; Bjorling et al., 2001; Huang and Reichardt, 2001; Pezet and McMahon, 2006; Girard et al., 2011; Jiang et al., 2013, 2014). NGF is a potent neurotrophin that exerts pleiotropic effects in the PNS and CNS through the tissue-specific expression of TrkA and $\mathrm{p} 75^{N T R}$ receptors. NGF regulates sensory and sympathetic neuronal development and maintenance and contributes to inflammation of somatic and visceral origin (Schnegelsberg et al., 2010; Frias et al., 2011; Ochodnicky et al., 2012). A large percentage of pelvic visceral afferent neurons, including bladder afferent neurons, exhibit neurotrophin receptors, including certain tyrosine kinase membrane receptors (Trk) for NGF and related substances (McMahon et al., 1994; Wright and Snider, 1995; Qiao and Vizzard, 2002a,b, 2005). TrkA- and TrkB-IR and Trk phosphorylation in bladder afferent neurons is increased after cystitis (Qiao and Vizzard, 2002b).

Nerve growth factor has an established role in urinary bladder inflammation (Vizzard, 2000b; Schnegelsberg et al., 2010), most likely contributing to increased voiding frequency (Dmitrieva and McMahon, 1996; Clemow et al., 1998; Chuang et al., 2001; Hu et al., 2005; Guerios et al., 2006; Zvara and Vizzard, 2007; Guerios et al., 2008). Administration of NGF intravesically (Dmitrieva et al., 1997), intrathecally (Yoshimura et al., 2006), intramuscularly (Zvara and Vizzard, 2007), or via adenovirusmediated delivery to the urinary bladder (Lamb et al., 2004) induces increased voiding frequency as well as afferent neuronal hyperexcitability in rodents. Additionally, scavenging strategies involving sequestration of NGF or its receptor TrkA, as well as administration of Trk inhibitors, reduces urinary frequency in rodent models of urinary bladder inflammation (Dmitrieva et al., 1997; Hu et al., 2005; Klinger and Vizzard, 2008). NGF is also thought to play a role in several LUT disorders such as PBS/IC (Lowe et al., 1997; Okragly et al., 1999), OAB (Kim et al., 2006; Liu and Kuo, 2009; Liu et al., 2009, 2010, 2011) and BOO 
(Liu and Kuo, 2008). In fact, increased levels of NGF have been detected in the urine and the urothelium of individuals with $\mathrm{PBS} / \mathrm{IC}, \mathrm{OAB}$, and other painful bladder conditions (Lowe et al., 1997; Okragly et al., 1999; Kuo et al., 2010). Additional NGFmediated changes may include: modulation of local inflammatory responses through recruitment of mast cells, upregulation of neuropeptide/receptor systems and ion channels and altered expression of other neurotrophins/receptor systems (Girard et al., 2010, 2011, 2012).

A humanized monoclonal antibody (i.e., tanezumab) binds to and blocks the effects of NGF and has been used in a proof of concept human study for PBS/IC (Evans et al., 2011). Tanezumab was first developed for the treatment of osteoarthritis of the hip and knee, but further clinical trials were stopped due to adverse side effects (Cruz, 2014). Treatment produced modest improvements in self-reported pain scores as well as decreases in the number of urgency and frequency episodes. However, adverse side effects were reported in some patients, including paraesthesia (i.e., tingling skin), hyperesthesia (i.e., abnormal increase in sensitivity to stimuli), and migraines (Cruz, 2014).

\section{NEUROCHEMISTRY OF MICTURITION PATHWAYS}

Bladder afferents contain a number of neuroactive compounds including multiple neuropeptides (e.g., CGRP, SP, neurokinin A, neurokinin B, VIP, PACAP, cholecystokinin, enkephalins) (de Groat et al., 1983; Donovan et al., 1983; Keast and De Groat, 1992; Vizzard, 2000c, 2001; Arms and Vizzard, 2011; Merrill et al., 2013a). These neuropeptides are mainly expressed in small diameter, C-fiber afferents (de Groat et al., 1983; Donovan et al., 1983; Keast and De Groat, 1992; Vizzard, 2000c, 2001; Arms and Vizzard, 2011; Merrill et al., 2013a). The following sections will focus on the expression, distribution and functional plasticity of two members of the VIP/secretin/glucagon family of hormones in micturition reflex pathways: PACAP and VIP. The contributions of other peptides are described elsewhere (Arms and Vizzard, 2011).

Neuropeptides, expressed in afferent pathways to the LUT, exhibit either excitatory or inhibitory actions (Arms and Vizzard, 2011). Other, non-neural, sources of peptides in the LUT include the urothelium. For example, there is evidence of expression and functional activity by the VIP-PACAP family of peptides as well as the CRH family of peptides in the urothelium (Braas et al., 2006; LaBerge et al., 2006; Birder and Andersson, 2013; Hanna-Mitchell et al., 2014). The balance of peptides in LUT pathways can be affected by disease, neural injury and target organ inflammation. This change in balance of peptides can, conceivably, shift the LUT reflexes to a hyper- or a hypoactive reflex state (Arms and Vizzard, 2011). Functional changes in the micturition reflex that are demonstrated with urinary bladder inflammation (Vizzard, 2000a,c, 2001), PBS/IC, (Braas et al., 2006; de Groat and Yoshimura, 2009), OAB (Yoshimura et al., 2008), detrusor overactivity secondary to BOO (Andersson, 2006a,b), stress (Lutgendorf et al., 2000; Klausner et al., 2005; Robbins and Ness, 2008; Merrill et al., 2013b; Merrill and Vizzard,
2014; Mingin et al., 2014, 2015) or Parkinson's disease (Hamill et al., 2012) may reflect a change in the balance of peptides in LUT reflex pathways.

\section{PITUITARY ADENYLATE CYCLASE-ACTIVATING POLYPEPTIDE (PACAP) AND PAC1, VPAC1, VPAC2 RECEPTORS}

Pituitary adenylate cyclase-activating polypeptide is a member of the VIP/secretin/glucagon family of super hormones that was originally isolated from hypothalami based on its stimulation of anterior pituitary AC activity (Ogi et al., 1990; Arimura, 1998). The rat PACAP precursor protein undergoes post-translational processing to produce two, $\propto$-amidated forms: PACAP38 and PACAP27 (Kimura et al., 1990; Ohkubo et al., 1992; Okazaki et al., 1995; Arimura, 1998; Braas et al., 1998). The distribution of these two forms is tissue-specific with PACAP38 being the predominate form (Arimura et al., 1991; Arimura, 1998). PACAP38 is highly conserved among mammalian species underscoring its important involvement in cell signaling, modulation and trophic functions in the nervous and endocrine systems (Moller et al., 1997b; Arimura, 1998). There are three distinct G-protein-coupled receptors for PACAP and VIP: PAC1, VPAC1, and VPAC2 (Ishihara et al., 1992; Hashimoto et al., 1993; Hosoya et al., 1993; Lutz et al., 1993; Spengler et al., 1993; Inagaki et al., 1994). The expression of PAC1 and VPAC receptors is tissueand cell type-specific (May and Braas, 1995; Braas and May, 1996, 1999; Beaudet et al., 1998, 2000; Braas et al., 1998; May et al., 1998; DiCicco-Bloom et al., 2000). After G-protein-coupled $\mathrm{PAC} 1$ receptor activation and signaling at the plasma membrane, the receptor complex is often rapidly internalized via endocytic vesicles for trafficking into various intracellular compartments and pathways. PACAP mediates its diverse cellular functions through internalization of its cognate G-protein-coupled PAC1 receptor and endosomal signaling (May and Parsons, 2017).

\section{PACAP AND PAC1 RECEPTOR NEURONAL FUNCTIONS IN THE LUT}

Pituitary adenylate cyclase-activating polypeptide peptides exhibit diverse functions in many organ systems (e.g., endocrine, nervous, urinary, gastrointestinal, cardiovascular systems) and PACAP peptides are widely expressed in CNS and PNS, including sensory and autonomic ganglia (Koves et al., 1990, 1991; Arimura et al., 1991; Ghatei et al., 1993; Masuo et al., 1993; Tatsuno et al., 1994; May and Braas, 1995; Portbury et al., 1995; Shiotani et al., 1995; Braas and May, 1996, 1999; Holgert et al., 1996; Klimaschewski et al., 1996; Sundler et al., 1996; Brandenburg et al., 1997; Moller et al., 1997a,b; Nogi et al., 1997; Arimura, 1998; Beaudet et al., 1998, 2000; Braas et al., 1998; May et al., 1998; Cheppudira et al., 2009). PACAP-IR is expressed in nerve fibers within the urinary bladder smooth muscle, suburothelial nerve plexus and surrounding blood vessels (Fahrenkrug and Hannibal, 1998b). PACAP expression is significantly reduced in 
the urinary tract (i.e., ureter, bladder, and urethra) by neonatal capsaicin treatment delivered intraperitoneally, suggesting these fibers are derived from small diameter, C-fiber neurons (Fahrenkrug and Hannibal, 1998b). PACAP is expressed in DRG under control conditions and PACAP expression is increased after nerve injury or inflammation (Zhang et al., 1995, 1996; Larsen et al., 1997; Moller et al., 1997a; Vizzard, 2000c). Immunohistochemistry studies that demonstrated PACAP expression in LUT pathways and increased expression after SCI or bladder inflammation used both monoclonal and polyclonal PACAP antisera. Specificity of these reagents was confirmed with antibody preabsorption with PACAP $(20 \mathrm{mg} / \mathrm{ml})$ peptide (Hannibal et al., 1995; Calupca et al., 2000; Vizzard, 2000c) and in PACAP PA $^{-/}$mice (Girard et al., 2006). Using behavioral and neurological tests, we have demonstrated that $\mathrm{PACAP}^{-/-}$ and $\mathrm{VIP}^{-/-}$mice exhibit functional distinctions between the knockout genotypes. These results suggest that PACAP and VIP have evolved to possess distinct biological activities with the respective knockout phenotypes representing deficits unmitigated by the actions of the complementary related peptide (Girard et al., 2006).

\section{PACAP-MEDIATED EFFECTS ON UROTHELIUM}

A disruption to the barrier function of the urothelium (Negrete et al., 1996; Zeidel, 1996) may occur with disorders and injury that affect the bladder including PBS/IC or spinal cord injury (Lavelle et al., 2000; Apodaca et al., 2003, 2007). This loss of barrier integrity may contribute to the altered sensory processing (i.e., allodynia) observed in cystitis (i.e., pain with low to moderate bladder distention). The urothelium expresses PAC1 receptors and with stimulation, releases ATP to stimulate receptors on underlying sensory nerve fibers in the suburothelial plexus (Girard et al., 2008b). ATP release was evoked by PACAP27, PACAP38, and VIP application to cultured urothelial cells whereas PACAP27 and PAC1 receptor antagonism blocked ATP release (Girard et al., 2008b). PACAP signaling through PAC1 receptors may regulate micturition reflex function at the level of the urothelium (Girard et al., 2008b).

\section{PACAP OR VIP KNOCKOUT (-/-) MICE EXHIBIT ALTERED MICTURITION REFLEXES}

Mice with a genetic disruption or deletion of PACAP or VIP exhibit altered bladder and somatic function. $\mathrm{PACAP}^{+/-}$and $\mathrm{PACAP}^{-/-}$mice display reduced mechanical sensitivity in the pelvic and hindpaw regions as determined with von Frey monofilament testing (May and Vizzard, 2010). These differences may reflect distinct roles for VIP and PACAP in bladder sensory function and referred somatic sensation in the mouse. In contrast to somatic mechanosensitivity differences, both $\mathrm{PACAP}^{-/-}$and $\mathrm{VIP}^{-/-}$mice exhibited urinary bladder hypertrophy (Jensen et al., 2008; May and Vizzard, 2010). Cystometric analyses in
$\mathrm{PACAP}^{-/-}$and $\mathrm{VIP}^{-/-}$mice demonstrated increased bladder capacity, void volume, and longer duration between micturition events (i.e., intercontraction interval) (May and Vizzard, 2010) (Studeny et al., 2008). In addition to urinary bladder hypertrophy and increased bladder mass, $\mathrm{VIP}^{-/-}$mice have increased permeability to urea, increased basal expression of NGF and an exaggerated pro-inflammatory response (Girard et al., 2008a; Jensen et al., 2008; Studeny et al., 2008). Additionally, studies suggest an increase in bladder afferent activity in lumbosacral DRG in $\mathrm{VIP}^{-/-}$mice demonstrated with a marker of cellular activation (i.e., phosphorylated cAMP response-element binding protein) (Jensen et al., 2008). Given that $\mathrm{PACAP}^{-/-}$and $\mathrm{VIP}^{-/-}$ mice are global knockout models, the contributions of these peptides to LUT function from CNS or PNS sites of action must both be considered.

Urinary bladder dysfunction presents a major problem in the clinical management of patients suffering from a large number of neurological injuries (e.g., upper motor neuron disease after spinal cord injury, stroke), disorders (e.g., multiple sclerosis, Parkinson's disease) and chronic pain syndromes (e.g., $\mathrm{PBS} / \mathrm{IC})$. Information related to the normal organization of the micturition reflex and neuroplasticity with injury, disease and/or inflammation has the tremendous potential to increase our understanding of bladder disorders, to identify novel targets and to develop new therapeutic approaches.

\section{CYCLOPHOSPHAMIDE (CYP)-INDUCED CYSTITIS}

The etiology of PBS/IC is unknown. Thus, there is no universally accepted animal model for PBS/IC and no one model completely mimics all signs and symptoms of PBS/IC (Westropp and Buffington, 2002). CYP-induced cystitis is one of the most widely used animal models to study various aspects of the human condition, PBS/IC (Figure 2). CYP is an urotoxic anti-tumor agent that requires metabolism in the liver by cytochrome P50 (Boucher et al., 2000; Batista et al., 2006; Wantuch et al., 2007) and is then metabolized into acrolein, the urinary metabolite (Boucher et al., 2000; Eichel et al., 2001; Batista et al., 2006). It has been proposed that the urothelial damage that results from CYP treatment occurs by direct contact of the urothelium with acrolein (Figure 2B). This contact produces toxic effects on the bladder wall including edema, ulceration, neovascularization, necrosis, and hemorrhagic cystitis that are characteristic of treatment with CYP (Boucher et al., 2000; Eichel et al., 2001; Batista et al., 2006). CYP treatment has also been shown to produce changes in histological, permeability, and functional aspects of the urinary bladder (Boucher et al., 2000; Eichel et al., 2001; Batista et al., 2006). Functional changes after CYP administration include irritative voiding patterns in humans and animals, as well as an increase in micturition frequency in rodents (Cox, 1979; Maggi et al., 1992; Vizzard, 2000a,b, 2001; Eichel et al., 2001; Qiao and Vizzard, 2002b; Murray et al., 2004; Hu et al., 2005; Braas et al., 2006) (Figure 2C). CYP-induced cystitis is thought to alter bladder reflexes through stimulation of capsaicin-sensitive 


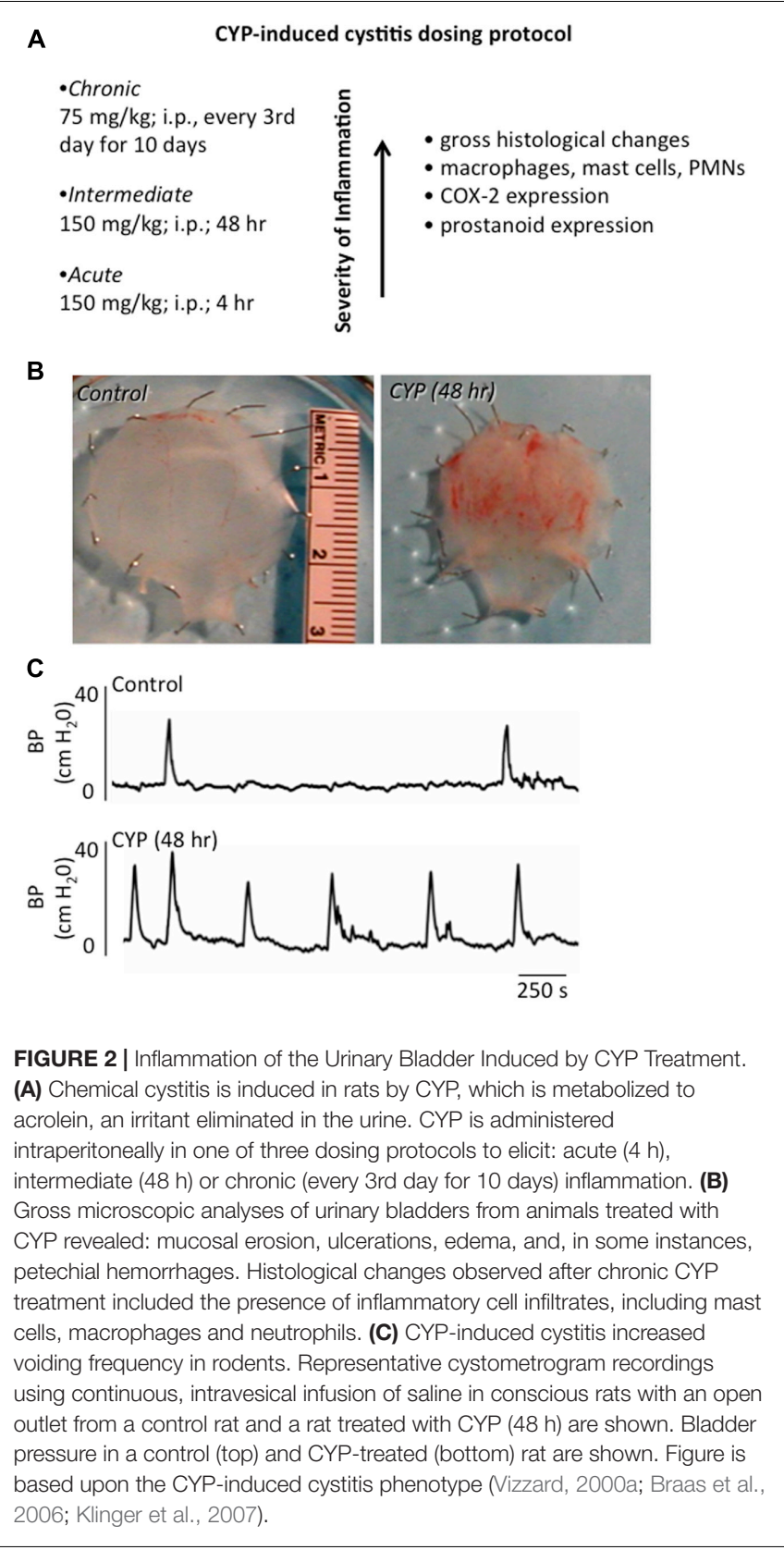

bladder afferent nerves (Yamamoto et al., 2012). CYP does not produce histological lesions or signs of inflammation in other tissues apart from the bladder, but does produce visceral pain similar to PBS/IC (Boucher et al., 2000; Wantuch et al., 2007). Our laboratory has found changes in urinary bladder function, somatic sensation, and the inflammatory milieu of the urinary bladder with various CYP treatment protocols in rodents (i.e., rats and mice) (Figure 2A). However, differences exist between the model and PBS/IC, including severity of inflammation at the level of the urinary bladder (Yamamoto et al., 2012). Although the naturally occurring FIC also models the human condition of PBS/IC (Westropp and Buffington, 2002), FIC cats are not available to most investigators and FIC cats usually represent established disease. Thus, determining early, initiating events and mechanisms involved in the disease process is difficult. The CYP-induced bladder inflammation model enables the testing of specific hypotheses related to LUT function.

\section{NEUROPLASTICITY OF PACAP/ RECEPTOR EXPRESSION AND FUNCTION WITH CYSTITIS}

It has been previously demonstrated that PACAP and its receptors are regulated by CYP-induced cystitis and may contribute to the development of urinary bladder dysfunction (Braas et al., 2006). Following a down regulation in transcript expression after acute (4 h) CYP-induced cystitis, PACAP and PAC1 transcript expression are dramatically upregulated in the urothelium, L6 and S1 DRG and detrusor smooth muscle after intermediate $(48 \mathrm{~h})$ or chronic (10 days) CYP-induced cystitis (Girard et al., 2008b). In contrast, VPAC1 and VPAC2 transcript expression remains upregulated in the urothelium and detrusor smooth muscle with acute and intermediate CYP-induced cystitis but down-regulation of VPAC2 transcript expression occurs with chronic treatment (Girard et al., 2008b). PACAP-IR in the spinal cord is increased in lumbosacral spinal cord regions [e.g., superficial laminae (I-II) of the DH, LCP of Lissauer, SPN] associated with LUT reflexes following CYP-induced cystitis (Vizzard, 2000c; Herrera et al., 2006). Additionally, numbers of bladder afferent cells exhibiting PACAP-IR increased in lumbosacral DRG following CYP-induced cystitis (Vizzard, 2000c).

Pharmacological studies using PAC1 receptor antagonists suggest that PACAP and its receptors may play a role in bladder dysfunction with bladder inflammation (Braas et al., 2006). Intrathecal (L6-S1) or intravesical administration of a PAC1 receptor antagonist, PACAP(6-38), increased bladder capacity but not intravesical pressure with CYP-induced cystitis (Braas et al., 2006). The different routes of administration (i.e., intrathecal and intravesical) with similar functional improvements suggest that PACAP(6-38) may be acting at multiple sites in the PNS and CNS. Intrathecal administration of PACAP(6-38) may be acting on superficial DH neurons to block PACAP release from C-fiber afferents, whereas, intravesical PACAP(6-38) may be targeting urothelial cells, suburothelial nerve fibers or detrusor smooth muscle cells (Braas et al., 2006). Intrathecal or intravesical blockade of PACAP/PAC1 may be a promising target to reduce voiding frequency with cystitis.

\section{PACAP EXPRESSION IN LUT WITH CYP-INDUCED CYSTITIS IN PACAP PROMOTER-DEPENDENT EGFP BAC TRANSGENIC MICE}

The PACAP-EGFP mouse strain is a transgenic line in which PACAP expressing cells and neurons are tagged with green fluorescent protein for easy visualization and tracking (Condro 
et al., 2016). PACAP-EGFP transgenic mice, Tg(Adcyap1EGFP)FB22Gsat/Mmucd (RRID:IMSR_MMRRC:012011) were generated using the BAC (RP24-35801) by the Gene Expression Nervous System Atlas (GENSAT) project and obtained from the Mutant Mouse Resource and Research Centers (Condro et al., 2016). The identification of PACAP expressing neurons has been challenging using standard immunocytochemistry and in situ hybridization techniques especially in areas with low peptide expression levels. The availability of these mice obviates these difficulties and will allow ready identification of these neurons and their fiber tracts to establish neurocircuits. The PACAPEGFP construct is regulated by the endogenous promoter. Therefore, it is possible to examine whether altered physiology, including stress, can differentially regulate specific neuronal PACAP populations in the CNS and PNS. We previously demonstrated an upregulation of PACAP expression in rodent micturition pathways following CYP-induced cystitis (Braas et al., 2006). We have subsequently examined the effects of CYP-induced cystitis ( $4 \mathrm{~h}, 48 \mathrm{~h}$, chronic) in PACAP promoterdependent EGFP BAC transgenic mice (gift from Dr. James A. Waschek, David Geffen School of Medicine, University of California, Los Angeles) (May et al., 2015, 2017a; Gonzalez et al., 2016). In control mice with no CYP treatment, low basal expression of PACAP-EGFP + fibers and cells was present in the superficial DH (L1, L2, L4-S1) and DRG (L1, L2, L6, S1) examined. After CYP-induced cystitis, numbers of PACAPEGFP + cells increased dramatically in spinal cord segments and DRG (L1, L2, L6, and S1) involved in micturition reflexes. PACAP-EGFP + nerve fibers were increased in density in the superficial laminae (I-II) of the DH and LCP of the lumbosacral spinal cord. Following CYP-induced cystitis, numbers of PACAPEGFP+ urothelial cells increased with the duration of cystitis (May et al., 2015, 2017a). After CYP-induced cystitis, additional changes in PACAP-EGFP+ nerves fibers and cells were observed in numerous supraspinal locations including: locus coeruleus, Barrington's nucleus, rostral ventrolateral medulla, PAG, raphe, and amygdala (May et al., 2015, 2017a). PACAP expression, in central and peripheral LUT pathways, may play a role in altered visceral sensation (allodynia) and/or increased voiding frequency in CYP-induced cystitis and in the chronic inflammatory pain syndrome, PBS/IC.

\section{ROLE OF NERVE GROWTH FACTOR (NGF) AND ASSOCIATED RECEPTORS IN LUT PLASTICITY}

Nerve growth factor is upregulated at the site of tissue injury, inflammation and/or target organ hypertrophy (Heumann et al., 1987; Lewin and Mendell, 1993; Meller and Gebhart, 1994; Dray, 1995; Woolf et al., 1997) and is also released from the target organ for TrkA binding and retrograde transport in DRG afferent neurons (Johnson et al., 1987). This increase in NGF expression or increased uptake of NGF in the DRG neurons may then induce increased production of neuropeptides (e.g., SP, CGRP, and PACAP) and alter sensory transduction (Donnerer et al., 1992; Woolf et al., 1997). A large percentage of pelvic visceral afferent neurons, including bladder afferent neurons, express neurotrophic factor receptors, including Trk and $\mathrm{p} 75^{N T R}$ for NGF and proNGF binding (McMahon et al., 1994; Wright and Snider, 1995; Qiao and Vizzard, 2002a,b). Similar to increased expression of NGF after cystitis, increased expression of TrkAand TrkB-IR and Trk phosphorylation in bladder afferent neurons has been demonstrated (Qiao and Vizzard, 2002b).

\section{NGF AND PACAP INTERACTIONS}

There is a growing body of literature that supports reciprocal regulatory interactions between NGF and PACAP in pheochromocytoma (PC) 12 cells and sensory ganglia. NGF is a positive regulator of PACAP expression in DRG cells (Jongsma Wallin et al., 2001). In rat PC12 cells, both NGF and PACAP can induce PC differentiation into a neuronal phenotype (Grumolato et al., 2003). Similarly, following transfection of PC12 cells with a PACAP promoter-luciferase construct, exogenously applied PACAP and/or NGF upregulated PACAP gene expression (Hashimoto et al., 1993; Yamamoto et al., 2012). In addition, the neurotrophins, NGF and/or BDNF can also facilitate expression of the PACAP-selective PAC1 receptor in CNS neurons (i.e., cerebellar granule cells) and PC12 cells (Jamen et al., 2002). In complementary studies, PACAP upregulated neurotrophin receptors, TrkA and TrkB, expression and/or phosphorylation in PC12 cells and CNS neurons (i.e., hippocampal neurons) in a Src-dependent manner (Lee et al., 2002). Using sympathetic neuroblasts, PACAP was shown to augment TrkA and TrkC expression in neuronal differentiation (DiCicco-Bloom et al., 2000). Reciprocal regulation of PACAP and NGF signaling pathways may be a feed-forward mechanism to amplify critical, physiological processes (e.g., survival or differentiation) during neuronal development or regeneration. In the context of urinary bladder inflammation, the same feed-forward mechanism may be detrimental resulting in the amplification of painful signals and exacerbation of target organ dysfunction.

\section{TRANSGENIC MOUSE MODEL OF CHRONIC, UROTHELIAL NGF OVEREXPRESSION (NGF-OE)}

Numerous studies have pointed to NGF as a molecule of interest in urinary bladder dysfunction and specifically, PBS/IC. Studies have demonstrated: (1) significant increases in urinary bladder NGF, after acute and chronic bladder inflammation induced by CYP (Vizzard, 2000b); (2) increased voiding frequency, reduced bladder capacity and increased Fos protein in lumbosacral spinal interneurons after exogenous delivery of NGF into the detrusor smooth muscle (Zvara and Vizzard, 2007); (3) reduced voiding frequency with NGF-scavenging agents in CYP-treated rats ( $\mathrm{Hu}$ et al., 2005) and (4) increased expression of NGF in urine of women and in the urothelium of bladder biopsies from women with PBS/IC (Lowe et al., 1997; Okragly et al., 1999). To more closely mimic the environment of chronic bladder inflammation and the clinical syndrome of PBS/IC, 
mice with chronic overexpression of NGF in the urothelium (uroplakin II NGF transgenic mice) were generated at Roche Palo Alto under the direction of Dr. Debra Cockayne and in collaboration with Dr. Henry Sun at New York University Medical School (Figures 3A,B) (Schnegelsberg et al., 2010). Mice with chronic, urothelial NGF-OE are valuable tools in determining the contribution of increased NGF expression in the urothelium to neural and functional plasticity of micturition reflexes (Figures 3D,E). Functionally, NGF-OE mice exhibit frequent urination and the presence of non-voiding bladder contractions as well as referred somatic pelvic hypersensitivity (Schnegelsberg et al., 2010) (Figure 3C). The electrical properties of the MPG neurons were unchanged suggesting that the efferent limb of the micturition reflex does not influence the voiding function in NGF-OE mice (Girard et al., 2012). Pleiotropic changes, subsequent to NGF-OE, including changes in the expression of growth factors, neuroactive compounds, receptors and ion channels (e.g., TRP channels) (Allen and Dawbarn, 2006; Pezet and McMahon, 2006) can also directly modulate pain and bladder/visceral sensory function and could contribute to altered urinary bladder function in NGF-OE mice (Yoshimura et al., 2002; Ford et al., 2006; Pezet and McMahon, 2006). For example, PACAP/VIP and receptor expression is changed in micturition pathways in NGF-OE mice (Arms et al., 2010). The PAC1 mRNA and PAC1-IR were upregulated whereas PACAP mRNA and PACAP-IR were decreased in urothelium of NGF-OE mice (Arms et al., 2010). In contrast, VPAC1 mRNA was decreased in both urothelium and detrusor smooth muscle of NGF-OE mice (Arms et al., 2010). VIP mRNA expression and VIP-IR were not altered in urinary bladder of NGF-OE mice (Arms et al., 2010). These additional changes in PACAP and associated receptors in micturition pathways of NGF-OE mice may also contribute to altered urinary bladder function in NGF-OE.

\section{CONTRIBUTIONS OF \\ PACAP/RECEPTOR SIGNALING TO INCREASED VOIDING FREQUENCY AND SOMATIC SENSITIVITY IN NGF-OE}

Chronic, urothelial NGF-OE, achieved through the use of a highly urothelium-specific uroplakin II promoter, produces neuroanatomical and functional changes in the LUT (Figure 3). Chronic, urothelial NGF-OE results in: (1) hyperinnervation in the urinary bladder; (2) increased voiding frequency; (3) increased presence and amplitude of non-voiding contractions during the filling phase and (4) increased referred somatic sensitivity (Schnegelsberg et al., 2010) (Figure 3). Previous sections have described the following key observations concerning PACAP/receptor signaling in the LUT: (1) PAC1immunoreactive fibers and neurons are present in the LUT including the urinary bladder and DRG (Braas et al., 2006); (2) PAC1 receptor is expressed by the DRG, urothelium, and detrusor smooth muscle (Braas et al., 2006); (3) PACAP increases detrusor contractions (Braas et al., 2006) and (4) PAC1 receptor antagonists, delivered intrathecally or intravesically, reduce voiding frequency in rodents with CYP-induced cystitis (Braas et al., 2006). Thus, we evaluated whether PACAP/receptor signaling contributes to increased voiding frequency and somatic sensitivity in NGF-OE mice (Girard et al., 2016). Intravesical administration of the PAC1 receptor antagonist, PACAP(6-38) $(300 \mathrm{nM})$, increased intercontraction interval (2.0-fold) and void volume (2.5-fold) and reduced pelvic sensitivity in NGF-OE mice (Girard et al., 2016) but had no effects in WT mice. $\mathrm{PACAP} /$ receptor signaling contributes to the increased voiding frequency and pelvic sensitivity observed in NGF-OE mice.

We have also determined whether additional changes in neuropeptides/receptors and growth factors/receptors are observed in LUT pathways in NGF-OE treated with CYP to induce cystitis (Girard et al., 2012). Quantitative PCR was used to determine NGF, BDNF and receptors (TrkA, TrkB, $\mathrm{p} 75^{N T R}$ ) and PACAP/VIP and receptors (PAC1, VPAC1, VPAC2) transcripts expression in LUT tissues from NGF-OE and WT mice with CYP-induced cystitis ( 4 h, 48 h, and chronic) (Girard et al., 2012). As expected, NGF mRNA in the urothelium was increased in control NGF-OE mice. However, urothelial expression of NGF mRNA in NGF-OE mice treated with CYP was not further increased but maintained with all durations of CYP (Girard et al., 2012). In contrast, CYP-induced cystitis in NGF-OE mice resulted in significant, additional changes in transcript expression for NGF, BDNF and receptors (TrkA, TrkB, $\mathrm{p} 75^{N T R}$ ) and PACAP/VIP and receptors (PAC1, VPAC1, VPAC2) in lumbosacral DRG and urinary bladder (e.g., urothelium, detrusor) that was dependent on the duration of cystitis (Girard et al., 2012). Conscious cystometry in unrestrained, NGF-OE mice treated with CYP demonstrated significant increases in voiding frequency above that observed in control NGF-OE mice underscoring that bladder functional changes were not saturated (Girard et al., 2011). These results suggest that chemical mediators (e.g., neurotrophins, neuropeptides) upregulated when CYP-induced cystitis is combined with NGF-OE can contribute to neurochemical and functional LUT plasticity in NGF-OE mice (Guerios et al., 2006, 2008; Arms et al., 2010, 2013; Schnegelsberg et al., 2010; Arms and Vizzard, 2011; Gonzalez et al., 2013, 2014a,b).

\section{PACAP MECHANISMS AND STRESS FACILITATE MICTURITION DYSREGULATION}

Patients with disorders of the LUT and associated disease states report worse symptoms during stress (Westropp and Buffington, 2002; Nazif et al., 2007). Several studies support this role in the exacerbation and likely the development of a number of LUT disorders including OAB syndrome and PBS/IC (Birder and Andersson, 2013). A majority of these patients report exacerbation of symptoms by clinical stress (Rothrock et al., 2001a,b), and experimental stress increases bladder pain and urgency in these individuals (Lutgendorf et al., 2000). In addition, animal models of stress demonstrate symptoms of bladder dysfunction (e.g., increased micturition frequency, urgency, pain) as well as anxiety-like behavior (Birder and Andersson, 2013) 

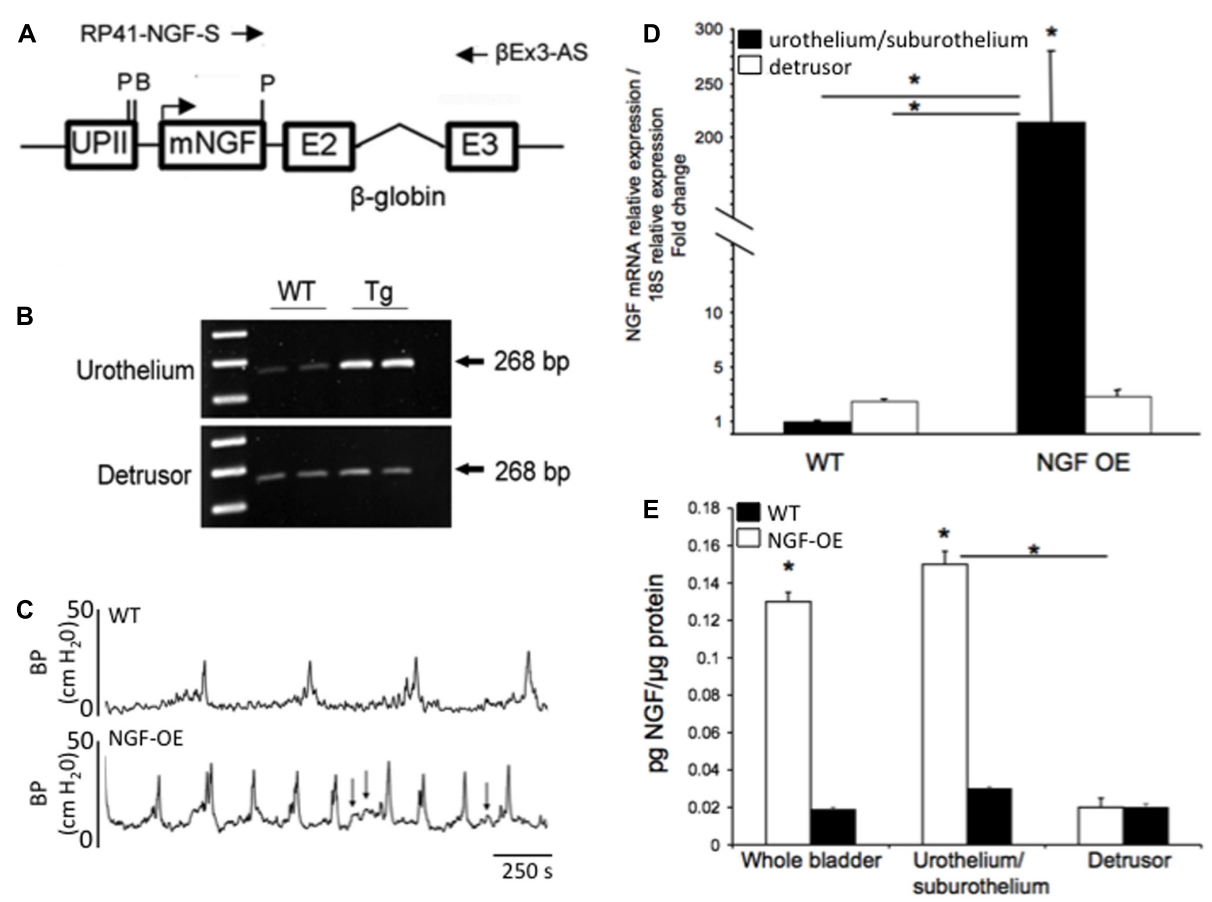

FIGURE 3 | Generation of NGF-overexpressing (NGF-OE) transgenic mice. (A) A 6,058 bp Notl fragment containing the uroplakin II (UPII)-NGFv2 transgene was microinjected into the pronuclei of fertilized C57BL/6J embryos to generate NGF-OE transgenic FO lines. BamHI and Pst I restriction sites, and the position of the primers used for genotyping (RP41-NGF-S and $\beta$ Ex3-AS) are indicated (Schnegelsberg et al., 2010). (B) Representative semi-quantitative RT-PCR data showing amplification of total NGF mRNA (268 bp) isolated from the urothelium or detrusor smooth muscle bladder of WT and NGF-OE mice (Schnegelsberg et al., 2010). (C) Open cystometry in conscious, unrestrained WT and NGF-OE mice demonstrated increased voiding frequency and non-voiding contractions (NVCs) in NGF-OE mice (Schnegelsberg et al., 2010). Representative cystometrogram traces from WT (top) and NGF-OE (bottom) mice during continuous intravesical infusion of room temperature saline. Bladder pressure $\left(\mathrm{BP}, \mathrm{cm} \mathrm{H}_{2} \mathrm{O}\right)$ is shown. Arrows indicate examples of NVCs. (D,E) Characterization of NGF mRNA and protein expression in urinary bladder from NGF-OE mice by quantitative RT-PCR and ELISAs (Cheppudira et al., 2008). (D) NGF transcript expression in urothelium/suburothelium and detrusor layers in NGF-OE and WT mice normalized to the housekeeping gene, $18 \mathrm{~S}$. Values are means \pm SEM. $* P \leq 0.001$ : NGF-OE urothelium/suburothelium vs. WT urothelium/suburothelium and detrusor (with horizontal bars) and within NGF-OE bladder layers (without horizontal bars) (Cheppudira et al., 2008). (E) Summary histogram of NGF protein expression in whole urinary bladder, urothelium/suburothelium, and detrusor layers in NGF-OE and WT mice. Values are means \pm SEM. ${ }^{*} P \leq 0.001$ : urothelium/suburothelium vs. detrusor from NGF-OE mice (with horizontal bars) and NGF-OE vs. WT (without horizontal bars) (Cheppudira et al., 2008).

that may be due, in part, to disruption of the HPA axis. Cortisol, by feeding back on the HPA axis, normally acts to attenuate inflammation; however, abnormalities in the feedback loop may cause dysregulation of the inflammatory response. Therefore, patients with bladder dysfunction disorders may have abnormalities in the HPA axis, and stress could be attributed to the increase in bladder symptoms, like urgency and pain, reported by these patients (Westropp and Buffington, 2002; Nazif et al., 2007). However, while stress has been associated with symptom aggravation, the pathophysiology underlying the effect of stress on urinary frequency and/or other voiding disorders remains unknown.

\section{STRESS EFFECTS ON THE STRUCTURE AND FUNCTION OF THE URINARY BLADDER}

Stress is known to exacerbate symptoms of PBS/IC, and exposure to stressors is related to the onset, progression and even outcome of many disease states including those related to the urinary bladder (Yamamoto et al., 2012). Several animal models of stress, including social stress (Miczek, 1979; Bhatnagar et al., 2006; Chang et al., 2009; Wood et al., 2009), immobilization stress (Spanos et al., 1997; Alexacos et al., 1999; Boucher et al., 2002, 2010), WAS (Cetinel et al., 2005; Robbins et al., 2007; Smith et al., 2011), and electric footshock (Imaki et al., 1991; Robbins and Ness, 2008; Black et al., 2009) produce morphological changes in the urinary bladder, urinary bladder dysfunction, urothelial barrier disruption, inflammation, and visceral sensitivity similar to signs and symptoms of PBS/IC.

\section{PSYCHOSOCIAL STRESS, ALTERED BEHAVIORS AND PHYSIOLOGICAL DISORDERS}

From the different modes of stress, psychosocial stress is the most familiar and relevant to everyday challenges and experiences. Unlike physical and metabolic stress which reflects perturbations of the homeostatic or resting state of the body, psychosocial stress results from our cognitive appraisal of 
some perceived threat (either real or imagined) and our judgment that we may not have the resources or means to overcome that challenge (Marshall and Garakani, 2002; TurnerCobb, 2005; FitzGerald et al., 2009; Lovallo, 2013; Mahon et al., 2013; Mihaljevic et al., 2016; Stephens et al., 2016). Classically, the heightened HPA axis coordinates sympathetic nervous system and cortisol adaptive responses to maintain homeostasis (allostasis) (Marshall and Garakani, 2002; TurnerCobb, 2005; FitzGerald et al., 2009; Lovallo, 2013; Mahon et al., 2013; Mihaljevic et al., 2016; Stephens et al., 2016); however, repeated challenges or the inability to attenuate stress signaling even when the dangers have dissipated can result in maladaptations and cumulative long-term damages (i.e., increased HPA and sympathetic reactivity; allostatic overload) that can manifest a variety of disorders (Marshall and Garakani, 2002; Turner-Cobb, 2005; FitzGerald et al., 2009; Lovallo, 2013; Mahon et al., 2013; Mihaljevic et al., 2016; Stephens et al., 2016). Psychosocial stressors engage the same pathways, and as in other stress modalities, the culmination of the many sustained psychosocial insults on individuals can increase the risk of a panoply of behavioral and physiological disorders including anxiety, depression, altered feeding preferences and behaviors, cardiovascular disease, obesity/metabolic diseases, gastrointestinal/urinary dysregulation, immunologic disorders and tumor progression (Herman et al., 1996, 2003, 2005, 2012, 2016, Marshall and Garakani, 2002; Turner-Cobb, 2005; Ressler and Mayberg, 2007; Jankord and Herman, 2008; FitzGerald et al., 2009; Jeanneteau et al., 2012; Lovallo, 2013; Mahon et al., 2013; Mihaljevic et al., 2016; Stephens et al., 2016). Juveniles and adolescents are particularly vulnerable to stress- and traumarelated effects on neural development; therefore, psychosocial stress during these life stages may have long-lasting consequences with enhanced risks for future behavioral and physiological disorders (Ressler and Mayberg, 2007). Thus, psychosocial stress has a broad impact on health and disease progression with substantial human and societal costs (Herman et al., 1996, 2003, 2005, 2012, 2016; Jankord and Herman, 2008; Jeanneteau et al., 2012).

Yet despite the consequences of psychosocial stressors, some of the fundamental neural mechanisms and pathways linking psychosocial stress to altered behaviors and physiological disorders are still unclear. Although a large body of data have implicated $\mathrm{CRH}$, arginine vasopressin, mineralocorticoid and glucocorticoid receptors, FKBP5 (a co-chaperone with hsp90 in GR heterocomplex), catecholamine metabolic enzymes, dopamine D2 receptor, and serotonin transporter isoforms transcripts in stress (Valentino, 1988; Marshall and Garakani, 2002; Turner-Cobb, 2005; FitzGerald et al., 2009; Lovallo, 2013; Mahon et al., 2013; Mihaljevic et al., 2016; Stephens et al., 2016), how altered expression of these genes contribute to the stress-related disorders remains to be elucidated. However, among central neuroregulators, PACAP and its cognate G protein coupled PAC1 receptor have recently been implicated as novel stress mediators. Ressler et al. (2011) published an elegant study that demonstrated the critical involvement of PACAP/PAC1 receptor expression and signaling in regulating psychological and physiological responses to traumatic stress. PACAP/PAC1 receptor transcripts are increased in specific limbic structures following RVS exposure; CNS PACAP signaling is anxiogenic and anorexic (Hammack et al., 2009; Lezak et al., 2014a,b; Missig et al., 2014; Roman et al., 2014), and chronic stressinduced anxiety-related behaviors can be blocked by PAC1 receptor antagonists. These PACAP-mediated responses are very similar to the anxiogenic effects of $\mathrm{CRH}$ suggesting that the two peptidergic systems may be integrated in limbic pathways. But importantly, unlike $\mathrm{CRH}$, recent work demonstrated that the PACAPergic system is dysregulated in PTSD in a sexspecific manner (Ressler et al., 2011). Recent studies suggest potential interactions between stress, PACAP and circulating gonadal hormones to differentially regulate the PACAPergic system in men and women with pathology including PTSD (King et al., 2017). Blood PACAP levels correlated with severity of PTSD symptoms and a single nucleotide polymorphism in the estrogen response element of the PAC1 receptor gene is predictive of PTSD diagnosis and symptoms in females (Ressler et al., 2011). These observations are consistent with the anxiolytic behavioral phenotype of PACAP knockout mice (Hashimoto et al., 2001; Otto et al., 2001; Hattori et al., 2012) and importantly, recent PACAP knockout studies have implicated PACAP as a unique mediator of emotional stressors (Hammack et al., 2009; Lezak et al., 2014a,b; Missig et al., 2014; Roman et al., 2014). From these aggregate results, the novel identification of PACAP/PAC1 receptor in emotional stress adds an important layer to existing neural circuits and mechanisms, which may further enhance understandings of stress and disease pathways.

A RVS paradigm has been previously used to examine PACAP and BDNF mRNA expression in the BNST (Hammack et al., 2009; King et al., 2017) (Figure 4A). This model of repeated stress was found to be anxiogenic, a result most likely mediated by BNST PACAP (Hammack et al., 2009; Lezak et al., 2014a,b; Missig et al., 2014; Roman et al., 2014). This paradigm involves seven consecutive days with daily exposure to one of five different stressors: oscillation, swim, footshock, restraint, and pedestal stress (Figure 4A). Oscillation stress involves rodents placed inside a chamber secured to a rotator on low to medium speed for $30 \mathrm{~min}$. Rodents are placed on an elevated platform for 30 min during pedestal stress. The other stressors include 5 min of forced monitored swimming, two $1.0 \mathrm{~mA} 5 \mathrm{~s}$ scrambled footshocks, and $60 \mathrm{~min}$ of restraint. Swim and footshock stressors are repeated during the 7-day paradigm (Hammack et al., 2009; King et al., 2017) (Figure 4A). When compared with other animal models of stress (e.g., resident intruder, immobilization, WAS, and electrical footshock) where the same stressors are presented daily, the RVS paradigm is unique in that various stressors are presented throughout the 7-day protocol, which may be more relevant to human daily life stressors. Other advantages of the RVS paradigm include: (1) lack of habituation because of novel stressor exposure; (2) consistent and robust changes in urinary bladder function (Merrill et al., 2013b; Merrill and Vizzard, 2014) (Figure 4D) and (3) reproducible decrease (10\%) in weight gain during RVS (Merrill et al., 2013b; Merrill and Vizzard, 2014) (Figures 4B,C). Furthermore, RVS paradigms are widely used to characterize the chronic 


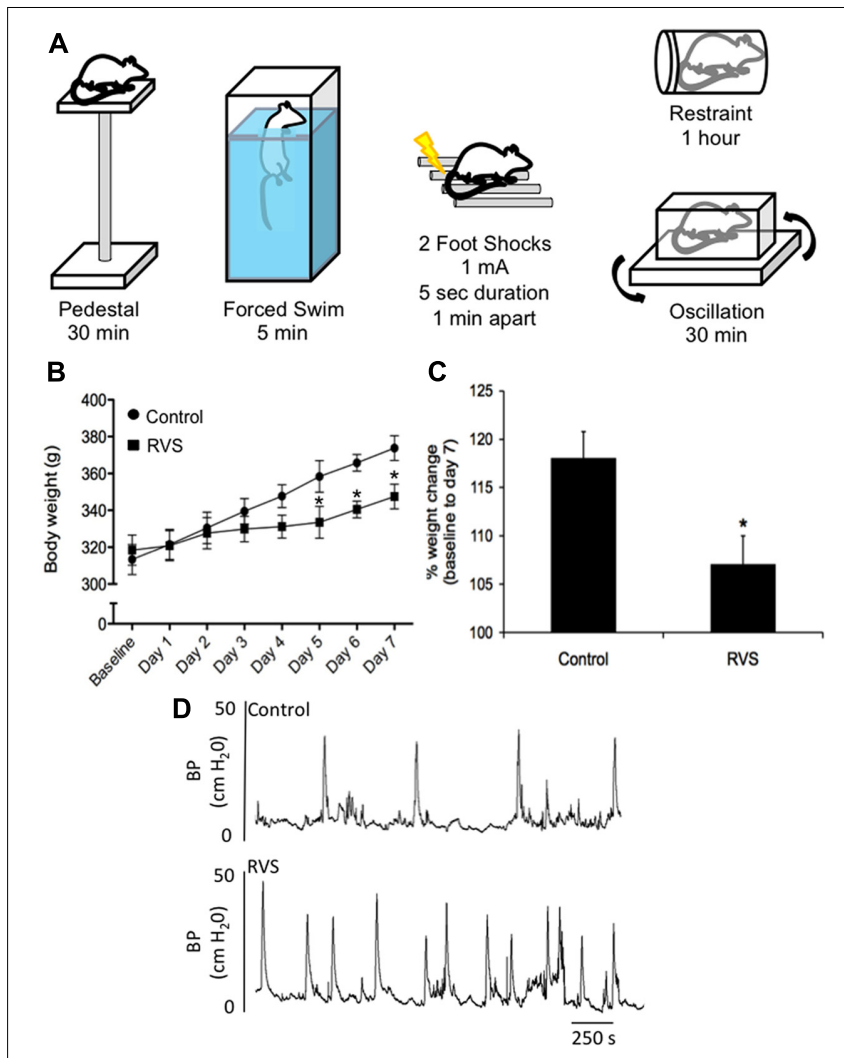

FIGURE 4 | Repeated variate stress (RVS) protocol (7 days). (A) Five different stressors and the duration of each stressor for each day they are administered in the RVS protocol (Merrill et al., 2013b; Longden et al., 2014a,b; Merrill and Vizzard, 2014). Swim and footshock stressors are repeated on the last 2 days of RVS. s, seconds; min, minutes. (B) Changes in body weight of rats during 7 days of RVS. On days 5-7 of stressor exposure, rats exposed to RVS exhibit significant weight gain attenuation compared with controls rats. Body weights were significantly $(P \leq 0.01)$ decreased in the RVS group on days $5-7$ of stress (Merrill et al., 2013b). (C) Percentage weight change from baseline body weight to body weight on day 7 of stressor exposure was significantly $(P \leq 0.01)$ decreased in rats exposed to RVS. Values are means \pm SEM, ${ }^{*} P \leq 0.01$ (Merrill et al., 2013b). (D) Representative cystometrogram recordings using continuous, intravesical infusion of saline in conscious rats with an open outlet from a control rat and a rat exposed to RVS demonstrate increased voiding frequency in rats exposed to RVS. Bladder pressure in a control (top) rat and RVS-exposed (bottom) rat are shown (Merrill et al., 2013b).

stress response, including: (1) CNS and PNS responses and neurochemical plasticity to chronic stress; (2) comorbidity of stress-related disorders; and (3) the role of the limbic system and neuroendocrine cascade in chronic stress (Herman et al., 1996, 2003, 2005, 2012, 2016; Jankord and Herman, 2008; Jeanneteau et al., 2012). We recently extended the use of the RVS protocol to characterize the effects on the autonomic nervous system and somatic sensitivity (Merrill et al., 2013b; Merrill and Vizzard, 2014). RVS produced (1) a decrease in bladder capacity and void volume and an increase in voiding frequency (Figure 4D); (2) enhanced referred somatic sensitivity of both the hindpaw and pelvic regions; and (3) changes in the inflammatory milieu (e.g., histamine, myeloperoxidase, NGF, CXCL12) of the urinary bladder (Merrill et al., 2013b; Merrill and Vizzard, 2014).

\section{RVS AND PACAP/RECEPTOR MECHANISMS CONTRIBUTE TO MICTURITION DYSFUNCTION}

Symptom exacerbation due to stress is prevalent in many disease states, including functional disorders of the urinary bladder (e.g., $\mathrm{OAB}, \mathrm{PBS} / \mathrm{IC}$ ) and may be partly due to disruption of the HPA axis (Westropp and Buffington, 2002; Nazif et al., 2007). The prevalence of micturition disorders is high among individuals with anxiety disorders (Perry et al., 2006; Fan et al., 2008; Coyne et al., 2009). However, the mechanisms underlying the effects of stress on micturition reflex function are unclear. Among central neuroregulators, PACAP (Adcyap1) and PAC1 receptor (Adcyap1r1) are novel stress mediators (Dore et al., 2013). PACAP/PAC1 receptor transcripts are increased in specific limbic structures following RVS exposure; CNS PACAP signaling is anxiogenic and anorexic, and chronic stressinduced anxiety-related behaviors can be blocked by PAC1 receptor antagonists (Hammack et al., 2009; Lezak et al., 2014a,b; Missig et al., 2014; Roman et al., 2014). We have recently characterized PACAP/PAC1 signaling in stress-induced urinary bladder dysfunction in mice (Gonzalez et al., 2016; May et al., 2017b). RVS induced urinary bladder hyperreflexia characterized by reduced void volumes, increased voiding frequency and decreased intercontraction void intervals (Merrill et al., 2013b; Merrill and Vizzard, 2014). In studies using a resident intruder paradigm in mice, similar changes in urinary bladder function (i.e., increased voiding frequency) have also been demonstrated (Mingin et al., 2014, 2015). Plasma corticosterone, a steroid hormone involved in the HPA axis secreted by the adrenal gland in rodents during stressor exposure, was determined in RVS and control mouse groups. Plasma corticosterone was significantly increased (5.2-fold) in mice with RVS compared to control mice (May et al., 2017b). We determined PACAP and PAC1 transcript and protein expression in the urinary bladder and lumbosacral DRG and spinal cord in RVS or control mouse groups. PACAP mRNA was significantly increased in lumbosacral (L1, L2, L6, S1) DRG following RVS but no changes were observed in PACAP protein. PACAP protein was significantly increased in urinary bladder and in the lumbosacral spinal cord (L6, S1) following RVS. No changes were observed in PAC1 mRNA expression in lumbosacral DRG examined; however, PAC1 protein was significantly increased in L6 an S1 DRG. Bladder function was assessed in RVS and control mouse groups using continuous, intravesical infusion of saline in conscious, unrestrained mice with an open outlet both before and after PAC1 blockade at the level of the urinary bladder (Gonzalez et al., 2016; May et al., 2017b). Intravesical administration of the PAC1 receptor antagonist, PACAP(6-38) (300 nM), significantly increased intercontraction interval (2.5-fold) and void volume (2.5-fold) in mice following RVS (Gonzalez et al., 2016; May et al., 2017b). We also evaluated the effect of PAC1 blockade at the level of the urinary bladder on pelvic and hindpaw 
sensitivity in RVS or control mouse groups using von Frey filament testing. Intravesical administration of PACAP(6-38) (300 nM) significantly reduced pelvic and hindpaw sensitivity in mice following RVS (Gonzalez et al., 2016; May et al., 2017b). $\mathrm{PACAP} /$ receptor signaling contributes to the increased voiding frequency and pelvic and hindpaw sensitivity observed in mice following RVS (Figure 5) (Braas et al., 2006). Ongoing studies are evaluating the potential overlap of CNS and PNS pathways involved in micturition reflex function and stress responses.

\section{PERSPECTIVES AND SIGNIFICANCE}

Numerous neuropeptide/receptor systems are expressed in CNS and PNS pathways that coordinate LUT reflexes [for review, see (Arms and Vizzard, 2011)]. PACAP is a member of the VIP/secretin/glucagon family of hormones, that is highly conserved across species and exists in two different isoforms, PACAP27 and PACAP38; the latter being the predominant form in most tissues and organ systems (Fahrenkrug et al., 1989; Arimura et al., 1991; Hannibal et al., 1995; Arimura, 1998; Fahrenkrug and Hannibal, 1998a,b). PACAP/receptor signaling underlies diverse neurological and physiological functions. Fahrenkrug and Hannibal (1998b) demonstrated that PACAP was expressed in C-fiber, unmyelinated nerve fibers in rat urinary tract. Given the involvement of C-fiber nerve pathways in the LUT following inflammation and neural injury (Fowler et al., 2008), we began to evaluate the anatomical distribution and function of PACAP/receptor signaling in rodent LUT pathways. PACAP (Adcyap1) and its cognate receptor, PAC1 (Adcyap1r1), have tissue-specific distributions in diverse systems including the LUT in both neural and non-neural components. Preclinical animal models including the CYP-induced bladder inflammation model, the transgenic mouse model of chronic urothelial NGF-OE and a RVS model are useful to evaluate underlying mechanisms contributing to urinary bladder dysfunction and pelvic pain associated with the clinical condition of PBS/IC (Figure 5). PACAP and associated receptors exhibit neuroplastic changes in expression and function with bladder inflammation or psychogenic stress and the PAC1 antagonist, PACAP(6-38), improves bladder function and reduces somatic sensitivity in preclinical models (Figure 5) (Braas et al., 2006). Changes in the PACAP/receptor system in micturition pathways may underlie and/or contribute to LUT dysfunction including the symptoms of increased voiding frequency, and pelvic pain. The $\mathrm{PACAP} /$ receptor system in micturition reflexes may represent a potential target for therapeutic intervention (Figure 5) (Braas et al., 2006).

We now draw attention to several areas where additional research is needed to advance our understanding of LUT function and dysfunction:

\section{The Need for Novel LUT Targets}

This review with its focus on the PACAP/receptor system in micturition pathways and its potential as a novel target to improve bladder function, underscores the need for additional LUT targets for intervention. Given the heterogeneity of PBS/IC syndrome, it is unlikely that one targeted intervention will work for all.

\section{The Need for Preclinical Models}

There are many challenges in identifying potential LUT targets. One challenge that continues to limit the identification and effectiveness of targets concerns the use of preclinical models and their relevance to human disease. For example, there is no consensus concerning the etiology of the disease syndrome, PBS/IC, which hinders the development and acceptance by the research community of preclinical models of PBS/IC (Lavelle et al., 2000; Sant and Hanno, 2001; Nazif et al., 2007; Quillin and Erickson, 2012; Saban, 2015). The models we have described in this review are several used to test hypotheses pertaining to LUT function and dysfunction. For example, the CYP model of bladder inflammation has grown in popularity and acceptance in the research community over the past 20 years. However, we still exercise caution and never consider the CYP model, a preclinical model of PBS/IC. Rather, CYP-induced cystitis is a bladder inflammation model that mirrors some signs and symptoms of the PBS/IC. The translational relevance of targets identified in preclinical models must be demonstrated in clinical studies.

\section{The Contribution of Stress in Bladder Dysfunction}

As discussed in this review, BPS/IC symptoms are often exacerbated by stress and correlate with symptom severity; however, cause and effect have not been addressed (Rothrock et al., 2001a,b; Birder and Andersson, 2013). There are a growing number of preclinical stress models being used to determine underlying mechanisms of stress-induced urinary bladder dysfunction (Miczek, 1979; Imaki et al., 1991; Spanos et al., 1997; Alexacos et al., 1999; Boucher et al., 2002, 2010; Cetinel et al., 2005; Bhatnagar et al., 2006; Robbins et al., 2007; Robbins and Ness, 2008; Black et al., 2009; Chang et al., 2009; Wood et al., 2009; Smith et al., 2011; Merrill et al., 2013b; Merrill and Vizzard, 2014). As an important first step, determining the overlap in the PNS and CNS neural structures and pathways that underlie stress responses and micturition reflexes will provide insight into the anatomical substrates underlying these processes. These studies should be followed by studies determining the neurochemical phenotype of participating cells in identified PNS and CNS substrates.

\section{The Function of the Lamina Propria Signaling Network}

Additional attention should be focused on unexplored and unappreciated aspects of the urinary bladder structure that could have profound influence on bladder function. As described previously, the lamina propria is located between the basement membrane of the mucosa and the detrusor muscle and is composed several types of cells, including: fibroblasts, adipocytes, interstitial cells, and afferent and efferent nerve endings (Andersson and McCloskey, 2014). Although increasing attention is being focused on the lamina propria, its contribution to bladder function is still emerging (McCloskey, 2010; Johnston 


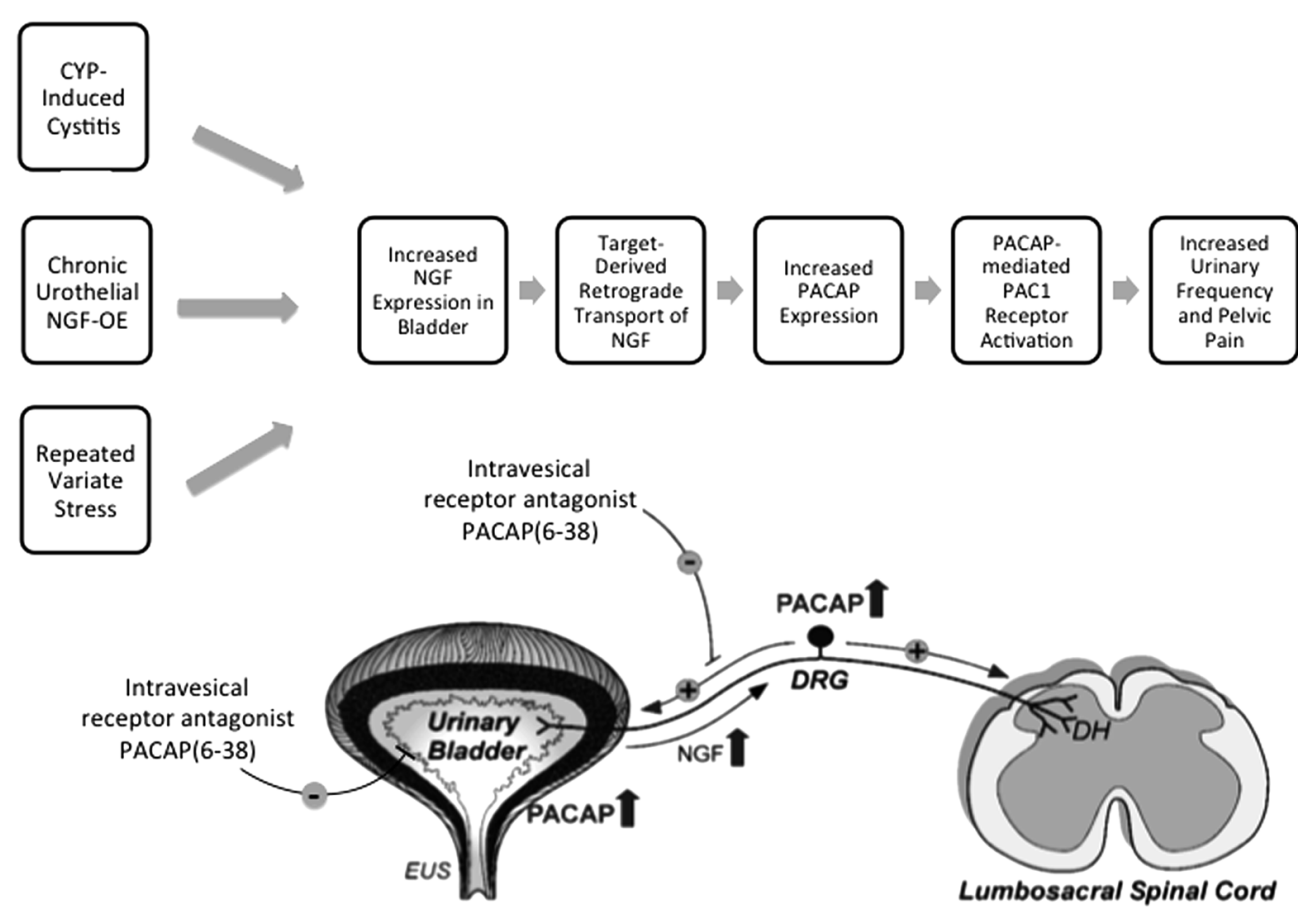

FIGURE 5 | The PACAP/receptor system in micturition reflexes: a potential target for therapeutic intervention. CYP-induced bladder inflammation model, the transgenic mouse model of chronic urothelial NGF-OE and a repeated variate stress model are useful to evaluate underlying mechanisms contributing to urinary bladder dysfunction and pelvic pain. Each model is associated with changes in NGF expression in the urinary bladder that can result in changes in the urinary bladder and be transported in a retrograde manner to lumbosacral dorsal root ganglia (DRG). PACAP and PAC1 receptor exhibit neuroplastic changes in expression and function with bladder inflammation, and stress. Intravesical instillation of the PAC1 receptor antagonist, PACAP(6-38), reduces voiding frequency and somatic sensitivity in preclinical models. The PACAP/receptor system in micturition reflexes may represent a potential target for therapeutic intervention to improve urinary bladder function and reduce pelvic pain. DH, dorsal horn; EUS, external urethral sphincter. Figure modified from Braas et al. (2006).

et al., 2012; Andersson and McCloskey, 2014). We have recently observed slow propagating waves of activity in the lamina propria network that displayed varying degrees of coupling (Heppner et al., 2017). Application of ATP or TRPV4 agonist, GSK1016790 (100 nM), increased the duration of $\mathrm{Ca}^{2+}$ events, the number of cells with $\mathrm{Ca}^{2+}$ events and the integrated $\mathrm{Ca}^{2+}$ activity corresponding to propagation of activity among cells in the lamina propria network (Heppner et al., 2017). These findings indicate that ATP and TRPV4 can activate cells in the laminar propria network, leading to the appearance of organized propagating wavefronts (Heppner et al., 2017). Continued analyses of the lamina propria network should include determining if neuropeptide/receptor systems can also activate cells in the lamina propria network and lead to propagating wavefronts. Such studies will help in understanding the potential functional importance of the lamina propria in health and disease.

\section{STUDIES INVOLVING ANIMAL RESEARCH}

The studies described from the Vizzard laboratory were performed in accordance with institutional and national guidelines and regulations. The University of Vermont
Institutional Animal Care and Use Committee approved all experimental protocols involving animal use. Animal care was under the supervision of the University of Vermont's Office of Animal Care Management in accordance with the Association for Assessment and Accreditation of Laboratory Animal Care (AAALAC) and National Institutes of Health guidelines. All efforts were made to minimize the potential for animal pain, stress or distress.

\section{AUTHOR CONTRIBUTIONS}

Conceived, discussed, and outlined the review: BG, KT, and MV. Reviewed the literature cited: BG, KT, and MV. Drafted and revised paper: BG, KT, and MV. Wrote the paper: BG, KT, and MV.

\section{FUNDING}

Research from the Vizzard laboratory described herein was funded by the National Institutes of Health (NIH) grants DK051369 (MV), DK060481 (MV). Additional support was also provided by grants from the National Center for Research Resources (5 P30 RR 032135) and the National Institute of General Medical Sciences (8 P30 GM 103498) from the NIH. 


\section{ACKNOWLEDGMENTS}

The authors thank current and former members of the Vizzard laboratory who have contributed to the studies described within including: Beatrice Girard, Mary Beth Klinger, Susan Malley, Jacqueline Ojala, Abbey Peterson, Kimberly Corrow, Katarina Zvarova, Peter Zvara, Li-ya Qiao, Bopaiah P. Cheppudira, Lauren Arms, Liana Merrill, and Eric Gonzalez. Gratitude is expressed to Dr. James A. Waschek, Department of Psychiatry and Behavioral Sciences, David Geffen School of Medicine, University of California Los Angeles for providing the PACAP-EGFP mice

\section{REFERENCES}

Alexacos, N., Pang, X., Boucher, W., Cochrane, D. E., Sant, G. R., and Theoharides, T. C. (1999). Neurotensin mediates rat bladder mast cell degranulation triggered by acute psychological stress. Urology 53, 1035-1040. doi: 10.1016/ S0090-4295(98)00627-X

Allen, S. J., and Dawbarn, D. (2006). Clinical relevance of the neurotrophins and their receptors. Clin. Sci. 110, 175-191. doi: 10.1042/CS20050161

Andersson, K. E. (2004). Mechanisms of Disease: central nervous system involvement in overactive bladder syndrome. Nat. Clin. Pract. Urol. 1, 103-108. doi: $10.1038 /$ ncpuro0021

Andersson, K. E. (2006a). Tachykinins: role in detrusor overactivity? Eur. Urol. 49, 423-425. doi: 10.1016/j.eururo.2005.11.021

Andersson, K. E. (2006b). Treatment-resistant detrusor overactivity-underlying pharmacology and potential mechanisms. Int. J. Clin. Pract. Suppl. 151, 8-16. doi: $10.1111 / j .1742-1241.2006 .01184 . x$

Andersson, K. E., and Arner, A. (2004). Urinary bladder contraction and relaxation: physiology and pathophysiology. Physiol. Rev. 84, 935-986. doi: 10.1152/ physrev.00038.2003

Andersson, K. E., and McCloskey, K. D. (2014). Lamina propria: the functional center of the bladder? Neurourol. Urodyn. 33, 9-16. doi: 10.1002/nau.22465

Andersson, K. E., and Wein, A. J. (2004). Pharmacology of the lower urinary tract: basis for current and future treatments of urinary incontinence. Pharmacol. Rev. 56, 581-631. doi: 10.1124/pr.56.4.4

Apodaca, G., Balestreire, E., and Birder, L. A. (2007). The uroepithelial-associated sensory web. Kidney Int. 72, 1057-1064. doi: 10.1038/sj.ki.5002439

Apodaca, G., Kiss, S., Ruiz, W., Meyers, S., Zeidel, M., and Birder, L. (2003). Disruption of bladder epithelium barrier function after spinal cord injury. Am. J. Physiol. Renal Physiol. 284, F966-F976. doi: 10.1152/ajprenal.00359.2002

Arimura, A. (1998). Perspectives on pituitary adenylate cyclase activating polypeptide (PACAP) in the neuroendocrine, endocrine, and nervous systems. Jpn. J. Physiol. 48, 301-331. doi: 10.2170/jjphysiol.48.301

Arimura, A., Somogyvari-Vigh, A., Miyata, A., Mizuno, K., Coy, D. H., and Kitada, C. (1991). Tissue distribution of PACAP as determined by RIA: highly abundant in the rat brain and testes. Endocrinology 129, 2787-2789. doi: 10 . 1210/endo-129-5-2787

Arms, L., Girard, B. M., Malley, S. E., and Vizzard, M. A. (2013). Expression and function of CCL2/CCR2 in rat micturition reflexes and somatic sensitivity with urinary bladder inflammation. Am. J. Physiol. Renal Physiol. 305, F111-122. doi: 10.1152/ajprenal.00139.2013

Arms, L., Girard, B. M., and Vizzard, M. A. (2010). Expression and function of CXCL12/CXCR4 in rat urinary bladder with cyclophosphamide-induced cystitis. Am. J. Physiol. Renal Physiol. 298, F589-F600. doi: 10.1152/ajprenal. 00628.2009

Arms, L., and Vizzard, M. A. (2011). Neuropeptides in lower urinary tract function. Handb. Exp. Pharmacol. 202, 395-423. doi: 10.1007/978-3-642-16499-6_19

Avelino, A., Charrua, A., Frias, B., Cruz, C., Boudes, M., de Ridder, D., et al. (2013). Transient receptor potential channels in bladder function. Acta Physiol. 207, 110-122. doi: 10.1111/apha.12021

Batista, C. K., Brito, G. A., Souza, M. L., Leitao, B. T., Cunha, F. Q., and Ribeiro, R. A. (2006). A model of hemorrhagic cystitis induced with acrolein in mice. Braz. J. Med. Biol. Res. 39, 1475-1481. doi: 10.1590/S0100-879X20060011 00011 used in the studies described. PACAP-EGFP BAC transgenic mice were generated by the GENSAT (Gene Expression Nervous System Atlas, Rockefeller University, New York, NY, United States). They thank Dr. Jan Fahrenkrug, University of Copenhagen, Copenhagen, Denmark, for his generosity in supplying the monoclonal PACAP antisera used in studies described. They also thank Dr. Victor May and Dr. Karen Braas, Department of Neurological Sciences, Larner College of Medicine at The University of Vermont, for their insightful discussions, assistance and ongoing collaborations directed at $\mathrm{PACAP} /$ receptor signaling in the autonomic nervous system.

Beaudet, M. M., Braas, K. M., and May, V. (1998). Pituitary adenylate cyclase activating polypeptide (PACAP) expression in sympathetic preganglionic projection neurons to the superior cervical ganglion. J. Neurobiol. 36, 325-336. doi: 10.1002/(SICI)1097-4695(19980905)36:3<325::AID-NEU2>3.0.CO;2-Y

Beaudet, M. M., Parsons, R. L., Braas, K. M., and May, V. (2000). Mechanisms mediating pituitary adenylate cyclase-activating polypeptide depolarization of rat sympathetic neurons. J. Neurosci. 20, 7353-7361.

Beckel, J. M., and Holstege, G. (2011). Neuroanatomy of the lower urinary tract. Handb. Exp. Pharmacol. 202, 99-116. doi: 10.1007/978-3-642-16499-6_6

Beckel, J. M., Kanai, A., Lee, S. J., de Groat, W. C., and Birder, L. A. (2006). Expression of functional nicotinic acetylcholine receptors in rat urinary bladder epithelial cells. Am. J. Physiol. Renal Physiol. 290, F103-F110. doi: 10.1152/ ajprenal.00098.2005

Bhatnagar, S., Vining, C., Iyer, V., and Kinni, V. (2006). Changes in hypothalamicpituitary-adrenal function, body temperature, body weight and food intake with repeated social stress exposure in rats. J. Neuroendocrinol. 18, 13-24. doi: 10.1111/j.1365-2826.2005.01375.x

Birder, L., and Andersson, K. E. (2013). Urothelial signaling. Physiol. Rev. 93, 653-680. doi: 10.1152/physrev.00030.2012

Birder, L. A. (2005). More than just a barrier: urothelium as a drug target for urinary bladder pain. Am. J. Physiol. Renal Physiol. 289, F489-F495. doi: 10. 1152/ajprenal.00467.2004

Birder, L. A., Andersson, K. E., Kanai, A. J., Hanna-Mitchell, A. T., and Fry, C. H. (2014). Urothelial mucosal signaling and the overactive bladder-ICI-RS 2013. Neurourol. Urodyn. 33, 597-601. doi: 10.1002/nau.22604

Birder, L. A., and de Groat, W. C. (2007). Mechanisms of disease: involvement of the urothelium in bladder dysfunction. Nat. Clin. Pract. Urol. 4, 46-54. doi: $10.1038 /$ ncpuro0672

Birder, L. A., Hanna-Mitchell, A. T., and Kanai, A. J. (2009). "Neural-epithelial communication and visceral pain," in Visceral Pain, ed. D.E. Bjorling (Kerala: Research Signpost), 45-70.

Bjorling, D. E., Jacobsen, H. E., Blum, J. R., Shih, A., Beckman, M., Wang, Z. Y., et al. (2001). Intravesical Escherichia coli lipopolysaccharide stimulates an increase in bladder nerve growth factor. BJU Int. 87, 697-702. doi: 10.1046/ j.1464-410x.2001.02138.x

Black, L. V., Ness, T. J., and Robbins, M. T. (2009). Effects of oxytocin and prolactin on stress-induced bladder hypersensitivity in female rats. J. Pain 10, 1065-1072. doi: $10.1016 /$ j.jpain.2009.04.007

Boucher, M., Meen, M., Codron, J. P., Coudore, F., Kemeny, J. L., and Eschalier, A. (2000). Cyclophosphamide-induced cystitis in freely-moving conscious rats: behavioral approach to a new model of visceral pain. J. Urol. 164, 203-208. doi: $10.1016 / \mathrm{S} 0022-5347(05) 67495-2$

Boucher, W., Kempuraj, D., Michaelian, M., and Theoharides, T. C. (2010). Corticotropin-releasing hormone-receptor 2 is required for acute stressinduced bladder vascular permeability and release of vascular endothelial growth factor. BJU Int. 106, 1394-1399. doi: 10.1111/j.1464-410X.2010.09237.x

Boucher, W. S., Letourneau, R., Huang, M., Kempuraj, D., Green, M., Sant, G. R., et al. (2002). Intravesical sodium hyaluronate inhibits the rat urinary mast cell mediator increase triggered by acute immobilization stress. J. Urol. 167, 380-384. doi: 10.1016/S0022-5347(05)65472-9

Braas, K. M., and May, V. (1996). Pituitary adenylate cyclase-activating polypeptides, PACAP-38 and PACAP-27, regulation of sympathetic neuron catecholamine, and neuropeptide $\mathrm{Y}$ expression through activation of type I 
PACAP/VIP receptor isoforms. Ann. N. Y. Acad. Sci. 805, 204-216; discussion 217-208. doi: 10.1111/j.1749-6632.1996.tb17484.x

Braas, K. M., and May, V. (1999). Pituitary adenylate cyclase-activating polypeptides directly stimulate sympathetic neuron neuropeptide Y release through $\mathrm{PAC}(1)$ receptor isoform activation of specific intracellular signaling pathways. J. Biol. Chem. 274, 27702-27710. doi: 10.1074/jbc.274.39. 27702

Braas, K. M., May, V., Harakall, S. A., Hardwick, J. C., and Parsons, R. L. (1998). Pituitary adenylate cyclase-activating polypeptide expression and modulation of neuronal excitability in guinea pig cardiac ganglia. J. Neurosci. 18, 9766-9779.

Braas, K. M., May, V., Zvara, P., Nausch, B., Kliment, J., Dunleavy, J. D., et al. (2006). Role for pituitary adenylate cyclase activating polypeptide in cystitisinduced plasticity of micturition reflexes. Am. J. Physiol. Regul. Integr. Comp. Physiol. 290, R951-R962. doi: 10.1152/ajpregu.00734.2005

Brandenburg, C. A., May, V., and Braas, K. M. (1997). Identification of endogenous sympathetic neuron pituitary adenylate cyclase-activating polypeptide (PACAP): depolarization regulates production and secretion through induction of multiple propeptide transcripts. J. Neurosci. 17, 4045-4055.

Calupca, M. A., Vizzard, M. A., and Parsons, R. L. (2000). Origin of pituitary adenylate cyclase-activating polypeptide (PACAP)-immunoreactive fibers innervating guinea pig parasympathetic cardiac ganglia. J. Comp. Neurol. 423, 26-39. doi: 10.1002/1096-9861(20000717)423:1<26::AID-CNE3>3.0. $\mathrm{CO} ; 2-\mathrm{C}$

Cetinel, S., Ercan, F., Cikler, E., Contuk, G., and Sener, G. (2005). Protective effect of melatonin on water avoidance stress induced degeneration of the bladder. J. Urol. 173, 267-270. doi: 10.1097/01.ju.0000145891.35810.56

Chang, A., Butler, S., Sliwoski, J., Valentino, R., Canning, D., and Zderic, S. (2009). Social stress in mice induces voiding dysfunction and bladder wall remodeling. Am. J. Physiol. Renal Physiol. 297, F1101-F1108. doi: 10.1152/ajprenal.90749. 2008

Cheng, C. L., and de Groat, W. C. (2004). The role of capsaicin-sensitive afferent fibers in the lower urinary tract dysfunction induced by chronic spinal cord injury in rats. Exp. Neurol. 187, 445-454. doi: 10.1016/j.expneurol.2004. 02.014

Cheppudira, B. P., Girard, B. M., Malley, S. E., Dattilio, A., Schutz, K. C., May, V., et al. (2009). Involvement of JAK-STAT signaling/function after cyclophosphamide-induced bladder inflammation in female rats. Am. J. Physiol. Renal Physiol. 297, F1038-F1044. doi: 10.1152/ajprenal.00110.2009

Cheppudira, B. P., Girard, B. M., Malley, S. E., Schutz, K. C., May, V., and Vizzard, M. A. (2008). Upregulation of vascular endothelial growth factor isoform VEGF-164 and receptors (VEGFR-2, Npn-1, and Npn-2) in rats with cyclophosphamide-induced cystitis. Am. J. Physiol. Renal Physiol. 295, F826-F836. doi: 10.1152/ajprenal.90305.2008

Chopra, B., Barrick, S. R., Meyers, S., Beckel, J. M., Zeidel, M. L., Ford, A. P., et al. (2005). Expression and function of bradykinin B1 and B2 receptors in normal and inflamed rat urinary bladder urothelium. J. Physiol. 562(Pt 3), 859-871. doi: 10.1113/jphysiol.2004.071159

Chuang, Y. C., Fraser, M. O., Yu, Y., Chancellor, M. B., de Groat, W. C., and Yoshimura, N. (2001). The role of bladder afferent pathways in bladder hyperactivity induced by the intravesical administration of nerve growth factor. J. Urol. 165, 975-979. doi: 10.1016/S0022-5347(05)66587-1

Clemow, D. B., Steers, W. D., McCarty, R., and Tuttle, J. B. (1998). Altered regulation of bladder nerve growth factor and neurally mediated hyperactive voiding. Am. J. Physiol. 275(4 Pt 2), R1279-F1286.

Cockayne, D. A., Dunn, P. M., Zhong, Y., Rong, W., Hamilton, S. G., Knight, G. E., et al. (2005). P2X2 knockout mice and P2X2/P2X3 double knockout mice reveal a role for the $\mathrm{P} 2 \mathrm{X} 2$ receptor subunit in mediating multiple sensory effects of ATP. J. Physiol. 567(Pt 2), 621-639. doi: 10.1113/jphysiol.2005.088435

Condro, M. C., Matynia, A., Foster, N. N., Ago, Y., Rajbhandari, A. K., Van, C., et al. (2016). High-resolution characterization of a PACAP-EGFP transgenic mouse model for mapping PACAP-expressing neurons. J. Comp. Neurol. 524, 3827-3848. doi: 10.1002/cne.24035

Cox, P. J. (1979). Cyclophosphamide cystitis-identification of acrolein as the causative agent. Biochem. Pharmacol. 28, 2045-2049. doi: 10.1016/00062952(79)90222-3

Coyne, K. S., Wein, A. J., Tubaro, A., Sexton, C. C., Thompson, C. L., Kopp, Z. S., et al. (2009). The burden of lower urinary tract symptoms: evaluating the effect of LUTS on health-related quality of life, anxiety and depression: EpiLUTS. BJU Int. 103 (Suppl. 3), 4-11. doi: 10.1111/j.1464-410X.2009.08371.x

Cruz, C. D. (2014). Neurotrophins in bladder function: what do we know and where do we go from here? Neurourol. Urodyn. 33, 39-45. doi: 10.1002/nau. 22438

de Groat, W. C. (1990). Central neural control of the lower urinary tract. Ciba Found Symp. 151, 27-44; discussion 44-56.

de Groat, W. C. (1993). Anatomy and physiology of the lower urinary tract. Urol. Clin. North Am. 20, 383-401.

de Groat, W. C., and Araki, I. (1999). Maturation of bladder reflex pathways during postnatal development. Adv. Exp. Med. Biol. 462, 253-263; discussion 311-220. doi: 10.1007/978-1-4615-4737-2_19

de Groat, W. C., Araki, I., Vizzard, M. A., Yoshiyama, M., Yoshimura, N., Sugaya, K., et al. (1998). Developmental and injury induced plasticity in the micturition reflex pathway. Behav. Brain Res. 92, 127-140. doi: 10.1016/S01664328(97)00185-X

de Groat, W. C., Kawatani, M., Hisamitsu, T., Lowe, I., Morgan, C., Roppolo, J., et al. (1983). The role of neuropeptides in the sacral autonomic reflex pathways of the cat. J. Auton. Nerv. Syst. 7, 339-350. doi: 10.1016/0165-1838(83)90087-5

de Groat, W. C., Nadelhaft, I., Milne, R. J., Booth, A. M., Morgan, C., and Thor, K. (1981). Organization of the sacral parasympathetic reflex pathways to the urinary bladder and large intestine. J. Auton. Nerv. Syst. 3, 135-160. doi: 10.1016/0165-1838(81)90059-X

De Groat, W. C., and Saum, W. R. (1972). Sympathetic inhibition of the urinary bladder and of pelvic ganglionic transmission in the cat. J. Physiol. 220, 297-314. doi: 10.1113/jphysiol.1972.sp009708

de Groat, W. C., and Wickens, C. (2013). Organization of the neural switching circuitry underlying reflex micturition. Acta Physiol. 207, 66-84. doi: 10.1111/ apha. 12014

de Groat, W. C., and Yoshimura, N. (2006). Mechanisms underlying the recovery of lower urinary tract function following spinal cord injury. Prog. Brain Res. 152, 59-84. doi: 10.1016/S0079-6123(05)52005-3

de Groat, W. C., and Yoshimura, N. (2009). Afferent nerve regulation of bladder function in health and disease. Handb. Exp. Pharmacol. 194, 91-138. doi: 10. 1007/978-3-540-79090-7_4

de Groat, W. C., and Yoshimura, N. (2010). Changes in afferent activity after spinal cord injury. Neurourol. Urodyn. 29, 63-76. doi: 10.1002/nau.20761

de Groat, W. C., and Yoshimura, N. (2012). Plasticity in reflex pathways to the lower urinary tract following spinal cord injury. Exp. Neurol. 235, 123-132. doi: 10.1016/j.expneurol.2011.05.003

Deckmann, K., Filipski, K., Krasteva-Christ, G., Fronius, M., Althaus, M., Rafiq, A., et al. (2014). Bitter triggers acetylcholine release from polymodal urethral chemosensory cells and bladder reflexes. Proc. Natl. Acad. Sci. U.S.A. 111, 8287-8292. doi: 10.1073/pnas.1402436111

DiCicco-Bloom, E., Deutsch, P. J., Maltzman, J., Zhang, J., Pintar, J. E., Zheng, J., et al. (2000). Autocrine expression and ontogenetic functions of the PACAP ligand/receptor system during sympathetic development. Dev. Biol. 219, 197-213. doi: 10.1006/dbio.2000.9604

Dmitrieva, N., and McMahon, S. B. (1996). Sensitisation of visceral afferents by nerve growth factor in the adult rat. Pain 66, 87-97. doi: 10.1016/0304-3959(96) 02993-4

Dmitrieva, N., Shelton, D., Rice, A. S., and McMahon, S. B. (1997). The role of nerve growth factor in a model of visceral inflammation. Neuroscience 78, 449-459. doi: 10.1016/S0306-4522(96)00575-1

Donnerer, J., Schuligoi, R., and Stein, C. (1992). Increased content and transport of substance $\mathrm{P}$ and calcitonin gene-related peptide in sensory nerves innervating inflamed tissue: evidence for a regulatory function of nerve growth factor in vivo. Neuroscience 49, 693-698. doi: 10.1016/0306-4522(92) 90237-V

Donovan, M. K., Winternitz, S. R., and Wyss, J. M. (1983). An analysis of the sensory innervation of the urinary system in the rat. Brain Res. Bull. 11, 321-324. doi: 10.1016/0361-9230(83)90168-5

Dore, R., Iemolo, A., Smith, K. L., Wang, X., Cottone, P., and Sabino, V. (2013). CRF mediates the anxiogenic and anti-rewarding, but not the anorectic effects of PACAP. Neuropsychopharmacology 38, 2160-2169. doi: 10.1038/npp. 2013.113

Dray, A. (1995). Inflammatory mediators of pain. Br. J. Anaesth. 75, 125-131. doi: $10.1093 / \mathrm{bja} / 75.2 .125$ 
Eichel, L., Scheidweiler, K., Kost, J., Shojaie, J., Schwarz, E., Messing, E. M., et al. (2001). Assessment of murine bladder permeability with fluorescein: validation with cyclophosphamide and protamine. Urology 57(6 Suppl. 1), 115. doi: 10. 1016/S0090-4295(01)01007-X

Elbadawi, A. (1996). Functional anatomy of the organs of micturition. Urol. Clin. North Am. 23, 177-210. doi: 10.1016/S0094-0143(05)70304-9

Evans, R. J., Moldwin, R. M., Cossons, N., Darekar, A., Mills, I. W., and Scholfield, D. (2011). Proof of concept trial of tanezumab for the treatment of symptoms associated with interstitial cystitis. J. Urol. 185, 1716-1721. doi: 10.1016/j.juro.2010.12.088

Fahrenkrug, J., and Hannibal, J. (1998a). PACAP in visceral afferent nerves supplying the rat digestive and urinary tracts. Ann. N. Y. Acad. Sci. 865, 542-546. doi: 10.1111/j.1749-6632.1998.tb11233.x

Fahrenkrug, J., and Hannibal, J. (1998b). Pituitary adenylate cyclase activating polypeptide immunoreactivity in capsaicin-sensitive nerve fibres supplying the rat urinary tract. Neuroscience 83, 1261-1272. doi: 10.1016/S0306-4522(97) 00474-0

Fahrenkrug, J., Palle, C., Jorgensen, J., and Ottesen, B. (1989). Regulatory peptides in the mammalian urogenital system. Experientia Suppl. 56, 362-381. doi: 10. 1007/978-3-0348-9136-3_19

Fan, Y. H., Lin, A. T., Wu, H. M., Hong, C. J., and Chen, K. K. (2008). Psychological profile of female patients with dysfunctional voiding. Urology 71, 625-629. doi: 10.1016/j.urology.2007.11.063

Ferguson, D. R., Kennedy, I., and Burton, T. J. (1997). ATP is released from rabbit urinary bladder epithelial cells by hydrostatic pressure changes-a possible sensory mechanism? J. Physiol. 505 (Pt 2), 503-511. doi: 10.1111/j.1469-7793. 1997.503bb.x

FitzGerald, L. Z., Kehoe, P., and Sinha, K. (2009). Hypothalamic-pituitary- adrenal axis dysregulation in women with irritable bowel syndrome in response to acute physical stress. West J. Nurs. Res. 31, 818-836. doi: 10.1177/0193945909339320

Ford, A. P., and Cockayne, D. A. (2011). ATP and P2X purinoceptors in urinary tract disorders. Handb. Exp. Pharmacol. 202, 485-526. doi: 10.1007/978-3-64216499-6_22

Ford, A. P., Gever, J. R., Nunn, P. A., Zhong, Y., Cefalu, J. S., Dillon, M. P., et al. (2006). Purinoceptors as therapeutic targets for lower urinary tract dysfunction. Br. J. Pharmacol. 147 (Suppl. 2), S132-S143. doi: 10.1038/sj.bjp.0706637

Forrest, S. L., Osborne, P. B., and Keast, J. R. (2014). Characterization of axons expressing the artemin receptor in the female rat urinary bladder: a comparison with other major neuronal populations. J. Comp. Neurol. 522, 3900-3927. doi: $10.1002 /$ cne. 23648

Fowler, C. J., Griffiths, D., and de Groat, W. C. (2008). The neural control of micturition. Nat. Rev. Neurosci. 9, 453-466. doi: 10.1038/nrn2401

Frias, B., Lopes, T., Pinto, R., Cruz, F., and Cruz, C. D. (2011). Neurotrophins in the lower urinary tract: becoming of age. Curr. Neuropharmacol. 9, 553-558. doi: $10.2174 / 157015911798376253$

Ghatei, M. A., Takahashi, K., Suzuki, Y., Gardiner, J., Jones, P. M., and Bloom, S. R. (1993). Distribution, molecular characterization of pituitary adenylate cyclaseactivating polypeptide and its precursor encoding messenger RNA in human and rat tissues. J. Endocrinol. 136, 159-166. doi: 10.1677/joe.0.1360159

Girard, B. A., Lelievre, V., Braas, K. M., Razinia, T., Vizzard, M. A., Ioffe, Y., et al. (2006). Noncompensation in peptide/receptor gene expression and distinct behavioral phenotypes in VIP- and PACAP-deficient mice. J. Neurochem. 99, 499-513. doi: 10.1111/j.1471-4159.2006.04112.x

Girard, B. M., Malley, S. E., Braas, K. M., May, V., and Vizzard, M. A. (2010). PACAP/VIP and receptor characterization in micturition pathways in mice with overexpression of NGF in urothelium. J. Mol. Neurosci. 42, 378-389. doi: 10.1007/s12031-010-9384-3

Girard, B. M., Malley, S. E., Braas, K. M., Waschek, J. A., May, V., and Vizzard, M. A. (2008a). Exaggerated expression of inflammatory mediators in vasoactive intestinal polypeptide knockout (VIP-/-) mice with cyclophosphamide (CYP)-induced cystitis. J. Mol. Neurosci. 36, 188-199. doi: 10.1007/s12031-0089084-4

Girard, B. M., Malley, S. E., Mathews, M. M., May, V., and Vizzard, M. A. (2016). Intravesical PAC1 receptor antagonist, PACAP(6-38), reduces urinary bladder frequency and pelvic sensitivity in NGF-OE mice. J. Mol. Neurosci. 59, 290-299. doi: 10.1007/s12031-016-0764-1

Girard, B. M., Malley, S. E., and Vizzard, M. A. (2011). Neurotrophin/receptor expression in urinary bladder of mice with overexpression of NGF in urothelium. Am. J. Physiol. Renal Physiol. 300, F345-F355. doi: 10.1152/ ajprenal.00515.2010

Girard, B. M., Tompkins, J. D., Parsons, R. L., May, V., and Vizzard, M. A. (2012). Effects of CYP-induced cystitis on PACAP/VIP and receptor expression in micturition pathways and bladder function in mice with overexpression of NGF in urothelium. J. Mol. Neurosci. 48, 730-743. doi: 10.1007/s12031-012-9834-1

Girard, B. M., Wolf-Johnston, A., Braas, K. M., Birder, L. A., May, V., and Vizzard, M. A. (2008b). PACAP-mediated ATP release from rat urothelium and regulation of PACAP/VIP and receptor mRNA in micturition pathways after cyclophosphamide (CYP)-induced cystitis. J. Mol. Neurosci. 36, 310-320. doi: 10.1007/s12031-008-9104-4

Gonzalez, E. J., Arms, L., and Vizzard, M. A. (2014a). The role(s) of cytokines/chemokines in urinary bladder inflammation and dysfunction. Biomed. Res. Int. 2014:120525. doi: 10.1155/2014/120525

Gonzalez, E. J., Girard, B., Braas, K. M., May, V., and Vizzard, M. A. (2016). "Neuroplasticity of PACAP expression and function in micturition reflex pathways," in Pituitary Adenylate Cyclase Activating Polypeptide - PACAP, eds D. Reglodi and A. Tamas (Cham: Springer International Publishing), 313-334.

Gonzalez, E. J., Girard, B. M., and Vizzard, M. A. (2013). Expression and function of transforming growth factor-beta isoforms and cognate receptors in the rat urinary bladder following cyclophosphamide-induced cystitis. Am. J. Physiol. Renal Physiol. 305, F1265-F1276. doi: 10.1152/ajprenal.00042.2013

Gonzalez, E. J., Merrill, L., and Vizzard, M. A. (2014b). Bladder sensory physiology: neuroactive compounds and receptors, sensory transducers, and target-derived growth factors as targets to improve function. Am. J. Physiol. Regul. Integr. Comp. Physiol. 306, R869-R878. doi: 10.1152/ajpregu.00030.2014

Griffiths, D. (2015). Neural control of micturition in humans: a working model. Nat. Rev. Urol. 12, 695-705. doi: 10.1038/nrurol.2015.266

Grumolato, L., Louiset, E., Alexandre, D., Ait-Ali, D., Turquier, V., Fournier, A., et al. (2003). PACAP and NGF regulate common and distinct traits of the sympathoadrenal lineage: effects on electrical properties, gene markers and transcription factors in differentiating PC12 cells. Eur. J. Neurosci. 17, 71-82. doi: 10.1046/j.1460-9568.2003.02426.x

Guerios, S. D., Wang, Z. Y., and Bjorling, D. E. (2006). Nerve growth factor mediates peripheral mechanical hypersensitivity that accompanies experimental cystitis in mice. Neurosci. Lett. 392, 193-197. doi: 10.1016/j.neulet. 2005.09.026

Guerios, S. D., Wang, Z. Y., Boldon, K., Bushman, W., and Bjorling, D. E. (2008). Blockade of NGF and trk receptors inhibits increased peripheral mechanical sensitivity accompanying cystitis in rats. Am. J. Physiol. Regul. Integr. Comp. Physiol. 295, R111-R122. doi: 10.1152/ajpregu.00728.2007

Hamill, R. W., Tompkins, J. D., Girard, B. M., Kershen, R. T., Parsons, R. L., and Vizzard, M. A. (2012). Autonomic dysfunction and plasticity in micturition reflexes in human alpha-synuclein mice. Dev. Neurobiol. 72, 918-936. doi: $10.1002 /$ dneu.20978

Hammack, S. E., Cheung, J., Rhodes, K. M., Schutz, K. C., Falls, W. A., Braas, K. M., et al. (2009). Chronic stress increases pituitary adenylate cyclaseactivating peptide (PACAP) and brain-derived neurotrophic factor (BDNF) mRNA expression in the bed nucleus of the stria terminalis (BNST): roles for PACAP in anxiety-like behavior. Psychoneuroendocrinology 34, 833-843. doi: 10.1016/j.psyneuen.2008.12.013

Hanna-Mitchell, A. T., Wolf-Johnston, A., Roppolo, J. R., Buffington, T. C., and Birder, L. A. (2014). Corticotropin-releasing factor family peptide signaling in feline bladder urothelial cells. J. Endocrinol. 222, 113-121. doi: 10.1530/JOE13-0422

Hannibal, J., Mikkelsen, J. D., Clausen, H., Holst, J. J., Wulff, B. S., and Fahrenkrug, J. (1995). Gene expression of pituitary adenylate cyclase activating polypeptide (PACAP) in the rat hypothalamus. Regul. Pept. 55, 133-148. doi: 10.1016/0167-0115(94)00099-J

Heppner, T. J., Hennig, G. W., Nelson, M. T., and Vizzard, M. A. (2017). Rhythmic calcium events in the lamina propria network of the urinary bladder of rat pups. Front. Neurosci. 11:87. doi: 10.3389/fnsys.2017.00087

Hashimoto, H., Ishihara, T., Shigemoto, R., Mori, K., and Nagata, S. (1993). Molecular cloning and tissue distribution of a receptor for pituitary adenylate cyclase-activating polypeptide. Neuron 11, 333-342. doi: 10.1016/08966273(93)90188-W

Hashimoto, H., Shintani, N., Tanaka, K., Mori, W., Hirose, M., Matsuda, T., et al. (2001). Altered psychomotor behaviors in mice lacking pituitary adenylate 
cyclase-activating polypeptide (PACAP). Proc. Natl. Acad. Sci. U.S.A. 98, 13355-13360. doi: 10.1073/pnas.231094498

Hattori, S., Takao, K., Tanda, K., Toyama, K., Shintani, N., Baba, A., et al. (2012). Comprehensive behavioral analysis of pituitary adenylate cyclase-activating polypeptide (PACAP) knockout mice. Front. Behav. Neurosci. 6:58. doi: 10. 3389/fnbeh.2012.00058

Herman, J. P., Figueiredo, H., Mueller, N. K., Ulrich-Lai, Y., Ostrander, M. M., Choi, D. C., et al. (2003). Central mechanisms of stress integration: hierarchical circuitry controlling hypothalamo-pituitary-adrenocortical responsiveness. Front. Neuroendocrinol. 24, 151-180. doi: 10.1016/j.yfrne.2003. 07.001

Herman, J. P., McKlveen, J. M., Ghosal, S., Kopp, B., Wulsin, A., Makinson, R., et al. (2016). Regulation of the hypothalamic-pituitary-adrenocortical stress response. Compr. Physiol. 6, 603-621. doi: 10.1002/cphy.c150015

Herman, J. P., McKlveen, J. M., Solomon, M. B., Carvalho-Netto, E., and Myers, B. (2012). Neural regulation of the stress response: glucocorticoid feedback mechanisms. Braz. J. Med. Biol. Res. 45, 292-298. doi: 10.1590/S0100879X2012007500041

Herman, J. P., Ostrander, M. M., Mueller, N. K., and Figueiredo, H. (2005). Limbic system mechanisms of stress regulation: hypothalamo-pituitary-adrenocortical axis. Prog. Neuropsychopharmacol. Biol. Psychiatry 29, 1201-1213. doi: 10.1016/ j.pnpbp.2005.08.006

Herman, J. P., Prewitt, C. M., and Cullinan, W. E. (1996). Neuronal circuit regulation of the hypothalamo-pituitary-adrenocortical stress axis. Crit. Rev. Neurobiol. 10, 371-394. doi: 10.1615/CritRevNeurobiol.v10.i3-4.50

Herrera, G. M., Braas, K. M., May, V., and Vizzard, M. A. (2006). PACAP enhances mouse urinary bladder contractility and is upregulated in micturition reflex pathways after cystitis. Ann. N. Y. Acad. Sci. 1070, 330-336. doi: 10.1196/annals. 1317.040

Heumann, R., Lindholm, D., Bandtlow, C., Meyer, M., Radeke, M. J., Misko, T. P., et al. (1987). Differential regulation of mRNA encoding nerve growth factor and its receptor in rat sciatic nerve during development, degeneration, and regeneration: role of macrophages. Proc. Natl. Acad. Sci. U.S.A. 84, 8735-8739. doi: 10.1073 /pnas.84.23.8735

Holgert, H., Holmberg, K., Hannibal, J., Fahrenkrug, J., Brimijoin, S., Hartman, B. K., et al. (1996). PACAP in the adrenal gland-relationship with choline acetyltransferase, enkephalin and chromaffin cells and effects of immunological sympathectomy. Neuroreport 8, 297-301. doi: 10.1097/00001756-19961220000059

Holstege, G. (2005). Micturition and the soul. J. Comp. Neurol. 493, 15-20. doi: $10.1002 / \mathrm{cne} .20785$

Holstege, G., and Mouton, L. J. (2003). Central nervous system control of micturition. Int. Rev. Neurobiol. 56, 123-145. doi: 10.1016/S0074-7742(03) 56004-4

Hosoya, M., Onda, H., Ogi, K., Masuda, Y., Miyamoto, Y., Ohtaki, T., et al. (1993). Molecular cloning and functional expression of rat cDNAs encoding the receptor for pituitary adenylate cyclase activating polypeptide (PACAP). Biochem. Biophys. Res. Commun. 194, 133-143. doi: 10.1006/bbrc.1993.1795

Hou, X. H., Hyun, M., Taranda, J., Huang, K. W., Todd, E., Feng, D., et al. (2016). Central control circuit for context-dependent micturition. Cell 167, 73-86. e12. doi: $10.1016 /$ j.cell.2016.08.073

Hu, V. Y., Zvara, P., Dattilio, A., Redman, T. L., Allen, S. J., Dawbarn, D., et al. (2005). Decrease in bladder overactivity with REN1820 in rats with cyclophosphamide induced cystitis. J. Urol. 173, 1016-1021. doi: 10.1097/01. ju.0000155170.15023.e5

Huang, E. J., and Reichardt, L. F. (2001). Neurotrophins: roles in neuronal development and function. Annu. Rev. Neurosci. 24, 677-736. doi: 10.1146/ annurev.neuro.24.1.677

Imaki, T., Nahan, J. L., Rivier, C., Sawchenko, P. E., and Vale, W. (1991). Differential regulation of corticotropin-releasing factor mRNA in rat brain regions by glucocorticoids and stress. J. Neurosci. 11, 585-599.

Inagaki, N., Yoshida, H., Mizuta, M., Mizuno, N., Fujii, Y., Gonoi, T., et al. (1994). Cloning and functional characterization of a third pituitary adenylate cyclase-activating polypeptide receptor subtype expressed in insulin-secreting cells. Proc. Natl. Acad. Sci. U.S.A. 91, 2679-2683. doi: 10.1073/pnas.91. 7.2679

Ishihara, T., Shigemoto, R., Mori, K., Takahashi, K., and Nagata, S. (1992). Functional expression and tissue distribution of a novel receptor for vasoactive intestinal polypeptide. Neuron 8, 811-819. doi: 10.1016/0896-6273(92) 90101-I

Jamen, F., Bouschet, T., Laden, J. C., Bockaert, J., and Brabet, P. (2002). Upregulation of the PACAP type-1 receptor (PAC1) promoter by neurotrophins in rat PC12 cells and mouse cerebellar granule cells via the Ras/mitogen-activated protein kinase cascade. J. Neurochem. 82, 1199-1207. doi: 10.1046/j.1471-4159. 2002.01124.x

Janig, W., and Morrison, J. F. (1986). Functional properties of spinal visceral afferents supplying abdominal and pelvic organs, with special emphasis on visceral nociception. Prog. Brain Res. 67, 87-114. doi: 10.1016/S0079-6123(08) 62758-2

Jankord, R., and Herman, J. P. (2008). Limbic regulation of hypothalamo-pituitaryadrenocortical function during acute and chronic stress. Ann. N. Y. Acad. Sci. 1148, 64-73. doi: 10.1196/annals. 1410.012

Jeanneteau, F. D., Lambert, W. M., Ismaili, N., Bath, K. G., Lee, F. S., Garabedian, M. J., et al. (2012). BDNF and glucocorticoids regulate corticotrophin-releasing hormone (CRH) homeostasis in the hypothalamus. Proc. Natl. Acad. Sci. U.S.A. 109, 1305-1310. doi: 10.1073/pnas.1114122109

Jensen, D. G., Studeny, S., May, V., Waschek, J., and Vizzard, M. A. (2008). Expression of phosphorylated cAMP response element binding protein ( $\mathrm{p}$ CREB) in bladder afferent pathways in VIP-/ - mice with cyclophosphamide (CYP)-induced cystitis. J. Mol. Neurosci. 36, 299-309. doi: 10.1007/s12031-0089045-y

Jiang, Y. H., Liu, H. T., and Kuo, H. C. (2014). Decrease of urinary nerve growth factor but not brain-derived neurotrophic factor in patients with interstitial cystitis/bladder pain syndrome treated with hyaluronic Acid. PLOS ONE 9:e91609. doi: 10.1371/journal.pone.0091609

Jiang, Y. H., Peng, C. H., Liu, H. T., and Kuo, H. C. (2013). Increased pro-inflammatory cytokines, C-reactive protein and nerve growth factor expressions in serum of patients with interstitial cystitis/bladder pain syndrome. PLOS ONE 8:e76779. doi: 10.1371/journal.pone.0076779

Johnson, E. M. Jr., Taniuchi, M., Clark, H. B., Springer, J. E., Koh, S., et al. (1987). Demonstration of the retrograde transport of nerve growth factor receptor in the peripheral and central nervous system. J. Neurosci. 7, 923-929.

Johnston, L., Cunningham, R. M., Young, J. S., Fry, C. H., McMurray, G., Eccles, R., et al. (2012). Altered distribution of interstitial cells and innervation in the rat urinary bladder following spinal cord injury. J. Cell Mol. Med. 16, 1533-1543. doi: 10.1111/j.1582-4934.2011.01410.x

Jongsma Wallin, H., Danielsen, N., Johnston, J. M., Gratto, K. A., Karchewski, L. A., and Verge, V. M. (2001). Exogenous NT-3 and NGF differentially modulate PACAP expression in adult sensory neurons, suggesting distinct roles in injury and inflammation. Eur. J. Neurosci. 14, 267-282. doi: 10.1046/j.0953-816x.2001. 01641.x

Kawatani, M., Takeshige, C., and de Groat, W. C. (1990). Central distribution of afferent pathways from the uterus of the cat. J. Comp. Neurol. 302, 294-304. doi: $10.1002 / \mathrm{cne} .903020208$

Keast, J. R., and De Groat, W. C. (1992). Segmental distribution and peptide content of primary afferent neurons innervating the urogenital organs and colon of male rats. J. Comp. Neurol. 319, 615-623. doi: 10.1002/cne.9031 90411

Keast, J. R., Smith-Anttila, C. J., and Osborne, P. B. (2015). Developing a functional urinary bladder: a neuronal context. Front. Cell Dev. Biol. 3:53. doi: 10.3389/ fcell.2015.00053

Khadra, M. H., Satchell, P. M., and Vaughan, C. W. (1995). Sympathetic nervous system effects on feline bladder wall compliance throughout continence. Acta Physiol. Scand. 155, 31-39. doi: 10.1111/j.1748-1716.1995.tb 09945.x

Kim, J. C., Park, E. Y., Seo, S. I., Park, Y. H., and Hwang, T. K. (2006). Nerve growth factor and prostaglandins in the urine of female patients with overactive bladder. J. Urol. 175, 1773-1776; discussion 1776. doi: 10.1016/S0022-5347(05) 00992-4

Kimura, C., Ohkubo, S., Ogi, K., Hosoya, M., Itoh, Y., Onda, H., et al. (1990). A novel peptide which stimulates adenylate cyclase: molecular cloning and characterization of the ovine and human cDNAs. Biochem. Biophys. Res. Commun. 166, 81-89. doi: 10.1016/0006-291X(90)91914-E

King, S. B., Toufexis, D. J., and Hammack, S. E. (2017). Pituitary adenylate cyclase activating polypeptide (PACAP), stress, and sex hormones. Stress doi: 10.1080/ 10253890.2017.1336535 [Epub ahead of print]. 
Klausner, A. P., Streng, T., Na, Y. G., Raju, J., Batts, T. W., Tuttle, J. B., et al. (2005). The role of corticotropin releasing factor and its antagonist, astressin, on micturition in the rat. Auton. Neurosci. 123, 26-35. doi: 10.1016/j.autneu. 2005.08.003

Klimaschewski, L., Hauser, C., and Heym, C. (1996). PACAP immunoreactivity in the rat superior cervical ganglion in comparison to VIP. Neuroreport 7, 2797-2801. doi: 10.1097/00001756-199611040-00078

Klinger, M. B., Dattilio, A., and Vizzard, M. A. (2007). Expression of cyclooxygenase-2 in urinary bladder in rats with cyclophosphamide-induced cystitis. Am. J. Physiol. Regul. Integr. Comp. Physiol. 293, R677-R685. doi: 10.1152/ajpregu.00305.2007

Klinger, M. B., and Vizzard, M. A. (2008). Role of p75NTR in female rat urinary bladder with cyclophosphamide-induced cystitis. Am. J. Physiol. Renal Physiol. 295, F1778-F1789. doi: 10.1152/ajprenal.90501.2008

Koves, K., Arimura, A., Gorcs, T. G., and Somogyvari-Vigh, A. (1991). Comparative distribution of immunoreactive pituitary adenylate cyclase activating polypeptide and vasoactive intestinal polypeptide in rat forebrain. Neuroendocrinology 54, 159-169. doi: 10.1159/000125864

Koves, K., Arimura, A., Somogyvari-Vigh, A., Vigh, S., and Miller, J. (1990). Immunohistochemical demonstration of a novel hypothalamic peptide, pituitary adenylate cyclase-activating polypeptide, in the ovine hypothalamus. Endocrinology 127, 264-271. doi: 10.1210/endo-127-1-264

Kuo, H. C., Liu, H. T., Tyagi, P., and Chancellor, M. B. (2010). Urinary nerve growth factor levels in urinary tract diseases with or without frequency urgency symptoms. Low. Urin. Tract Symptoms 2, 88-94. doi: 10.1111/j.1757-5672.2010. 00065.x

LaBerge, J., Malley, S. E., Zvarova, K., and Vizzard, M. A. (2006). Expression of corticotropin-releasing factor and CRF receptors in micturition pathways after cyclophosphamide-induced cystitis. Am. J. Physiol. Regul. Integr. Comp. Physiol. 291(3), R692-703. doi: 10.1152/ajpregu.00086.2006

Lamb, K., Gebhart, G. F., and Bielefeldt, K. (2004). Increased nerve growth factor expression triggers bladder overactivity. J. Pain 5, 150-156. doi: 10.1016/j.jpain. 2004.01.001

Larsen, J. O., Hannibal, J., Knudsen, S. M., and Fahrenkrug, J. (1997). Expression of pituitary adenylate cyclase-activating polypeptide (PACAP) in the mesencephalic trigeminal nucleus of the rat after transsection of the masseteric nerve. Brain Res. Mol. Brain Res. 46, 109-117. doi: 10.1016/S0169-328X(96) 00279-3

Lavelle, J. P., Meyers, S. A., Ruiz, W. G., Buffington, C. A., Zeidel, M. L., and Apodaca, G. (2000). Urothelial pathophysiological changes in feline interstitial cystitis: a human model. Am. J. Physiol. Renal Physiol. 278, F540-F553.

Lee, F. S., Rajagopal, R., Kim, A. H., Chang, P. C., and Chao, M. V. (2002). Activation of Trk neurotrophin receptor signaling by pituitary adenylate cyclase-activating polypeptides. J. Biol. Chem. 277, 9096-9102. doi: 10.1074/jbc. M107421200

Lewin, G. R., and Mendell, L. M. (1993). Nerve growth factor and nociception. Trends Neurosci 16, 353-359. doi: 10.1016/0166-2236(93)90092-Z

Lezak, K. R., Roelke, E., Harris, O. M., Choi, I., Edwards, S., Gick, N., et al. (2014a). Pituitary adenylate cyclase-activating polypeptide (PACAP) in the bed nucleus of the stria terminalis (BNST) increases corticosterone in male and female rats. Psychoneuroendocrinology 45, 11-20. doi: 10.1016/j.psyneuen.2014.03.007

Lezak, K. R., Roman, C. W., Braas, K. M., Schutz, K. C., Falls, W. A., Schulkin, J., et al. (2014b). Regulation of bed nucleus of the stria terminalis PACAP expression by stress and corticosterone. J. Mol. Neurosci. 54, 477-484. doi: 10.1007/s12031-014-0269-8

Liu, H. T., Chancellor, M. B., and Kuo, H. C. (2009). Decrease of urinary nerve growth factor levels after antimuscarinic therapy in patients with overactive bladder. BJU Int. 103, 1668-1672. doi: 10.1111/j.1464-410X.2009.08380.x

Liu, H. T., Chen, C. Y., and Kuo, H. C. (2010). Urinary nerve growth factor levels in overactive bladder syndrome and lower urinary tract disorders. J. Formos. Med. Assoc. 109, 862-878. doi: 10.1016/S0929-6646(10)60133-7

Liu, H. T., Chen, C. Y., and Kuo, H. C. (2011). Urinary nerve growth factor in women with overactive bladder syndrome. BJU Int. 107, 799-803. doi: 10.1111/ j.1464-410X.2010.09585.x

Liu, H. T., and Kuo, H. C. (2008). Urinary nerve growth factor levels are increased in patients with bladder outlet obstruction with overactive bladder symptoms and reduced after successful medical treatment. Urology 72, 104-108; discussion 108. doi: 10.1016/j.urology.2008.01.069
Liu, H. T., and Kuo, H. C. (2009). Urinary nerve growth factor levels are elevated in patients with overactive bladder and do not significantly increase with bladder distention. Neurourol. Urodyn. 28, 78-81. doi: 10.1002/nau.20599

Longden, T. A., Dabertrand, F., Hill-Eubanks, D. C., Hammack, S. E., and Nelson, M. T. (2014a). Stress-induced glucocorticoid signaling remodels neurovascular coupling through impairment of cerebrovascular inwardly rectifying $\mathrm{K}+$ channel function. Proc. Natl. Acad. Sci. U.S.A. 111, 7462-7467. doi: 10.1073/ pnas. 1401811111

Longden, T. A., Hammack, S. E., and Nelson, M. T. (2014b). Channeling stress: inwardly-rectifying $\mathrm{K}+$ channels in stress and disease. Channels 8, 296-297. doi: $10.4161 /$ chan. 29969

Lovallo, W. R. (2013). Early life adversity reduces stress reactivity and enhances impulsive behavior: implications for health behaviors. Int. J. Psychophysiol. 90, 8-16. doi: 10.1016/j.ijpsycho.2012.10.006

Lowe, E. M., Anand, P., Terenghi, G., Williams-Chestnut, R. E., Sinicropi, D. V., and Osborne, J. L. (1997). Increased nerve growth factor levels in the urinary bladder of women with idiopathic sensory urgency and interstitial cystitis. Br. J. Urol. 79, 572-577. doi: 10.1046/j.1464-410X.1997.00097.x

Lutgendorf, S. K., Kreder, K. J., Rothrock, N. E., Ratliff, T. L., and Zimmerman, B. (2000). Stress and symptomatology in patients with interstitial cystitis: a laboratory stress model. J. Urol. 164, 1265-1269. doi: 10.1016/S0022-5347(05) 67152-2

Lutz, E. M., Sheward, W. J., West, K. M., Morrow, J. A., Fink, G., and Harmar, A. J. (1993). The VIP2 receptor: molecular characterisation of a cDNA encoding a novel receptor for vasoactive intestinal peptide. FEBS Lett. 334, 3-8. doi: 10.1016/0014-5793(93)81668-P

Maggi, C. A., Lecci, A., Santicioli, P., Del Bianco, E., and Giuliani, S. (1992). Cyclophosphamide cystitis in rats: involvement of capsaicin-sensitive primary afferents. J. Auton. Nerv. Syst. 38, 201-208. doi: 10.1016/0165-1838(92) 90031-B

Mahon, P. B., Zandi, P. P., Potash, J. B., Nestadt, G., and Wand, G. S. (2013). Genetic association of FKBP5 and CRHR1 with cortisol response to acute psychosocial stress in healthy adults. Psychopharmacology 227, 231-241. doi: $10.1007 / \mathrm{s} 00213-012-2956-\mathrm{x}$

Mallory, B., Steers, W. D., and De Groat, W. C. (1989). Electrophysiological study of micturition reflexes in rats. Am. J. Physiol. 257(2 Pt 2), R410-R421.

Marshall, R. D., and Garakani, A. (2002). Psychobiology of the acute stress response and its relationship to the psychobiology of post-traumatic stress disorder. Psychiatr. Clin. North Am. 25, 385-395. doi: 10.1016/S0193-953X(01)00005-3

Marson, L. (1997). Identification of central nervous system neurons that innervate the bladder body, bladder base, or external urethral sphincter of female rats: a transneuronal tracing study using pseudorabies virus. J. Comp. Neurol. 389, 584-602. doi: 10.1002/(SICI)1096-9861(19971229)389:4<584::AID-CNE4>3.0. $\mathrm{CO} ; 2-\mathrm{X}$

Masuo, Y., Suzuki, N., Matsumoto, H., Tokito, F., Matsumoto, Y., Tsuda, M., et al. (1993). Regional distribution of pituitary adenylate cyclase activating polypeptide (PACAP) in the rat central nervous system as determined by sandwich-enzyme immunoassay. Brain Res. 602, 57-63. doi: 10.1016/00068993(93)90241-E

May, V., Beaudet, M. M., Parsons, R. L., Hardwick, J. C., Gauthier, E. A., Durda, J. P., et al. (1998). Mechanisms of pituitary adenylate cyclase activating polypeptide (PACAP)-induced depolarization of sympathetic superior cervical ganglion (SCG) neurons. Ann. N. Y. Acad. Sci. 865, 164-175. doi: 10.1111/j. 1749-6632.1998.tb11175.x

May, V., and Braas, K. M. (1995). Pituitary adenylate cyclase-activating polypeptide (PACAP) regulation of sympathetic neuron neuropeptide $\mathrm{Y}$ and catecholamine expression. J. Neurochem. 65, 978-987. doi: 10.1046/j.14714159.1995.65030978.x

May, V., Mathews, M. E., Malley, S., Girard, B. M., Braas, K. M., Waschek, J. A., et al. (2015). "Pituitary adenylate cyclase-activating polypeptide (PACAP) expression in lower urinary tract pathways (LUT) with cyclophosphamide (CYP)-induced cystitis in PACAP promoter-dependent EGFP BAC transgenic mice," in Proceedings of 12th International Symposium on VIP, PACAP and Related Peptdies, Hong Kong

May, V., Mathews, M. E., Torres, N. S., McQuesten, J., Chang, P. L., Hauke, E., et al. (2017a). "Pituitary adenylate cyclase-activating polypeptide (PACAP) expression in lower urinary tract pathways (LUT) Following cyclophosphamide (CYP)-induced cystitis in PACAP promoter-dependent EGFP BAC transgenic 
mice," in Proceeding of 13th International Symposium on VIP, PACAP and Related Peptdies, Hong Kong.

May, V., Mathews, M. E., Torres, N. S., McQuesten, J., Chang, P. L., Hauke, E., et al. (2017b). "Role of PACAP/PAC1 signaling in micturition reflexes and somatic sensitivity following repeated variate stress (RVS) in PACAP promoterdependent EGFP BAC transgenic mice," in Proceedings of 12th International Symposium on VIP, PACAP and Related Peptdies, Hong Kong.

May, V., and Parsons, R. L. (2017). G protein-coupled receptor endosomal signaling and regulation of neuronal excitability and stress responses: signaling options and lessons from the PAC1 receptor. J. Cell. Physiol. 232, 698-706. doi: $10.1002 /$ jcp. 25615

May, V., and Vizzard, M. A. (2010). Bladder dysfunction and altered somatic sensitivity in PACAP-/- mice. J. Urol. 183, 772-779. doi: 10.1016/j.juro.2009. 09.077

McCloskey, K. D. (2010). Interstitial cells in the urinary bladder-localization and function. Neurourol. Urodyn. 29, 82-87. doi: 10.1002/nau.20739

McMahon, S. B. (1996). NGF as a mediator of inflammatory pain. Philos. Trans. $R$. Soc. Lond. B Biol. Sci. 351, 431-440. doi: 10.1098/rstb.1996.0039

McMahon, S. B., Armanini, M. P., Ling, L. H., and Phillips, H. S. (1994). Expression and coexpression of Trk receptors in subpopulations of adult primary sensory neurons projecting to identified peripheral targets. Neuron 12, 1161-1171. doi: 10.1016/0896-6273(94)90323-9

Meller, S. T., and Gebhart, G. F. (1994). Spinal mediators of hyperalgesia. Drugs 47 (Suppl. 5), 10-20; discussion 46-17. doi: 10.2165/00003495-199400475-00004

Mendell, L. M., Albers, K. M., and Davis, B. M. (1999). Neurotrophins, nociceptors, and pain. Microsc. Res. Tech. 45, 252-261. doi: 10.1002/(SICI)10970029(19990515/01)45:4/5<252::AID-JEMT9>3.0.CO;2-N

Merrill, L., Girard, B., Arms, L., Guertin, P., and Vizzard, M. A. (2013a). Neuropeptide/Receptor expression and plasticity in micturition pathways. Curr. Pharm. Des. 19, 4411-4422. doi: 10.2174/1381612811319240008

Merrill, L., Girard, B. M., May, V., and Vizzard, M. A. (2012). Transcriptional and translational plasticity in rodent urinary bladder TRP channels with urinary bladder inflammation, bladder dysfunction, or postnatal maturation. J. Mol. Neurosci. 48, 744-756. doi: 10.1007/s12031-012-9867-5

Merrill, L., Gonzalez, E. J., Girard, B. M., and Vizzard, M. A. (2016). Receptors, channels, and signalling in the urothelial sensory system in the bladder. Nat. Rev. Urol. 13, 193-204. doi: 10.1038/nrurol.2016.13

Merrill, L., Malley, S., and Vizzard, M. A. (2013b). Repeated variate stress in male rats induces increased voiding frequency, somatic sensitivity, and urinary bladder nerve growth factor expression. Am. J. Physiol. Regul. Integr. Comp. Physiol. 305, R147-R156. doi: 10.1152/ajpregu.00089.2013

Merrill, L., and Vizzard, M. A. (2014). Intravesical TRPV4 blockade reduces repeated variate stress-induced bladder dysfunction by increasing bladder capacity and decreasing voiding frequency in male rats. Am. J. Physiol. Regul. Integr. Comp. Physiol. 307, R471-R480. doi: 10.1152/ajpregu.00008.2014

Miczek, K. A. (1979). Chronic delta9-tetrahydrocannabinol in rats: effect on social interactions, mouse killing, motor activity, consummatory behavior, and body temperature. Psychopharmacology 60, 137-146. doi: 10.1007/BF00432284

Middleton, J. W., and Keast, J. R. (2004). Artificial autonomic reflexes: using functional electrical stimulation to mimic bladder reflexes after injury or disease. Auton. Neurosci. 113, 3-15. doi: 10.1016/j.autneu.2004.04.008

Mihaljevic, M., Zeljic, K., Soldatovic, I., Andric, S., Mirjanic, T., Richards, A., et al. (2016). The emerging role of the FKBP5 gene polymorphisms in vulnerabilitystress model of schizophrenia: further evidence from a Serbian population. Eur. Arch. Psychiatry Clin. Neurosci. doi: 10.1007/s00406-016-0720-7 [Epub ahead of print].

Mingin, G. C., Heppner, T. J., Tykocki, N. R., Erickson, C. S., Vizzard, M. A., and Nelson, M. T. (2015). Social stress in mice induces urinary bladder overactivity and increases TRPV1 channel-dependent afferent nerve activity. Am. J. Physiol. Regul. Integr. Comp. Physiol. 309, R629-R638. doi: 10.1152/ajpregu.00013.2015

Mingin, G. C., Peterson, A., Erickson, C. S., Nelson, M. T., and Vizzard, M. A. (2014). Social stress induces changes in urinary bladder function, bladder NGF content, and generalized bladder inflammation in mice. Am. J. Physiol. Regul. Integr. Comp. Physiol. 307, R893-R900. doi: 10.1152/ajpregu.00500.2013

Missig, G., Roman, C. W., Vizzard, M. A., Braas, K. M., Hammack, S. E., and May, V. (2014). Parabrachial nucleus (PBn) pituitary adenylate cyclase activating polypeptide (PACAP) signaling in the amygdala: implication for the sensory and behavioral effects of pain. Neuropharmacology 86, 38-48. doi: 10.1016/j.neuropharm.2014.06.022

Miyazato, M., Kadekawa, K., Kitta, T., Wada, N., Shimizu, N., de Groat, W. C., et al. (2017). New frontiers of basic science research in neurogenic lower urinary tract dysfunction. Urol. Clin. North Am. 44, 491-505. doi: 10.1016/j.ucl.2017.04.014

Moller, K., Reimer, M., Ekblad, E., Hannibal, J., Fahrenkrug, J., Kanje, M., et al. (1997a). The effects of axotomy and preganglionic denervation on the expression of pituitary adenylate cyclase activating peptide (PACAP), galanin and PACAP type 1 receptors in the rat superior cervical ganglion. Brain Res. 775, 166-182. doi: 10.1016/S0006-8993(97)00923-2

Moller, K., Reimer, M., Hannibal, J., Fahrenkrug, J., Sundler, F., and Kanje, M. (1997b). Pituitary adenylate cyclase-activating peptide (PACAP) and PACAP type 1 receptor expression in regenerating adult mouse and rat superior cervical ganglia in vitro. Brain Res. 775, 156-165. doi: 10.1016/S0006-8993(97)00937-2

Morgan, C., Nadelhaft, I., and de Groat, W. C. (1981). The distribution of visceral primary afferents from the pelvic nerve to Lissauer's tract and the spinal gray matter and its relationship to the sacral parasympathetic nucleus. J. Comp. Neurol. 201, 415-440. doi: 10.1002/cne.902010308

Morgan, C. W. (1990). Vasoactive intestinal polypeptide in sacral primary sensory pathways in the cat. J. Comp. Neurol. 10, 381-194.

Murray, E., Malley, S. E., Qiao, L. Y., Hu, V. Y., and Vizzard, M. A. (2004). Cyclophosphamide induced cystitis alters neurotrophin and receptor tyrosine kinase expression in pelvic ganglia and bladder. J. Urol. 172(6 Pt 1), 2434-2439. doi: 10.1097/01.ju.0000143549.29867.4e

Nadelhaft, I., and Vera, P. L. (1995). Central nervous system neurons infected by pseudorabies virus injected into the rat urinary bladder following unilateral transection of the pelvic nerve. J. Comp. Neurol. 359, 443-456. doi: 10.1002/ cne. 903590307

Nazif, O., Teichman, J. M., and Gebhart, G. F. (2007). Neural upregulation in interstitial cystitis. Urology 69(4 Suppl.), 24-33. doi: 10.1016/j.urology.2006. 08.1108

Negrete, H. O., Lavelle, J. P., Berg, J., Lewis, S. A., and Zeidel, M. L. (1996). Permeability properties of the intact mammalian bladder epithelium. Am. J. Physiol. 271(4 Pt 2), F886-F894.

Nogi, H., Hashimoto, H., Hagihara, N., Shimada, S., Yamamoto, K., Matsuda, T., et al. (1997). Distribution of mRNAs for pituitary adenylate cyclase-activating polypeptide (PACAP), PACAP receptor, vasoactive intestinal polypeptide (VIP), and VIP receptors in the rat superior cervical ganglion. Neurosci. Lett. 227, 37-40. doi: 10.1016/S0304-3940(97)00295-4

Noto, H., Roppolo, J. R., Steers, W. D., and de Groat, W. C. (1991). Electrophysiological analysis of the ascending and descending components of the micturition reflex pathway in the rat. Brain Res. 549, 95-105. doi: 10.1016/ 0006-8993(91)90604-T

Ochodnicky, P., Cruz, C. D., Yoshimura, N., and Cruz, F. (2012). Neurotrophins as regulators of urinary bladder function. Nat. Rev. Urol. 9, 628-637. doi: 10.1038/ nrurol.2012.178

Ogi, K., Kimura, C., Onda, H., Arimura, A., and Fujino, M. (1990). Molecular cloning and characterization of cDNA for the precursor of rat pituitary adenylate cyclase activating polypeptide (PACAP). Biochem. Biophys. Res. Commun. 173, 1271-1279. doi: 10.1016/S0006-291X(05)80924-6

Ohkubo, S., Kimura, C., Ogi, K., Okazaki, K., Hosoya, M., Onda, H., et al. (1992). Primary structure and characterization of the precursor to human pituitary adenylate cyclase activating polypeptide. DNA Cell Biol. 11,21-30. doi: 10.1089/ dna.1992.11.21

Okazaki, K., Itoh, Y., Ogi, K., Ohkubo, S., and Onda, H. (1995). Characterization of murine PACAP mRNA. Peptides 16, 1295-1299. doi: 10.1016/0196-9781(95) 02018-R

Okragly, A. J., Niles, A. L., Saban, R., Schmidt, D., Hoffman, R. L., Warner, T. F., et al. (1999). Elevated tryptase, nerve growth factor, neurotrophin-3 and glial cell line-derived neurotrophic factor levels in the urine of interstitial cystitis and bladder cancer patients. J. Urol. 161, 438-441; discussion 441-432.

Otto, C., Martin, M., Wolfer, D. P., Lipp, H. P., Maldonado, R., and Schutz, G. (2001). Altered emotional behavior in PACAP-type-I-receptor-deficient mice. Brain Res. Mol. Brain Res. 92, 78-84. doi: 10.1016/S0169-328X(01)00153-X

Perry, S., McGrother, C. W., Turner, K., and Leicestershire MRC Incontinence Study Group (2006). An investigation of the relationship between anxiety and depression and urge incontinence in women: development of a psychological 
model. Br. J. Health Psychol. 11(Pt 3), 463-482. doi: 10.1348/1359107 05X60742

Petruska, J. C., and Mendell, L. M. (2004). The many functions of nerve growth factor: multiple actions on nociceptors. Neurosci. Lett. 361, 168-171. doi: 10. 1016/j.neulet.2003.12.012

Pezet, S., and McMahon, S. B. (2006). Neurotrophins: mediators and modulators of pain. Annu. Rev. Neurosci. 29, 507-538. doi: 10.1146/annurev.neuro.29.051605. 112929

Portbury, A. L., McConalogue, K., Furness, J. B., and Young, H. M. (1995). Distribution of pituitary adenylyl cyclase activating peptide (PACAP) immunoreactivity in neurons of the guinea-pig digestive tract and their projections in the ileum and colon. Cell Tissue Res. 279, 385-392. doi: 10.1007/ BF00318496

Qiao, L., and Vizzard, M. A. (2002a). Up-regulation of tyrosine kinase (Trka, Trkb) receptor expression and phosphorylation in lumbosacral dorsal root ganglia after chronic spinal cord (T8-T10) injury. J. Comp. Neurol. 449, 217-230. doi: $10.1002 /$ cne. 10283

Qiao, L. Y., and Vizzard, M. A. (2002b). Cystitis-induced upregulation of tyrosine kinase (TrkA, TrkB) receptor expression and phosphorylation in rat micturition pathways. J. Comp. Neurol. 454, 200-211. doi: 10.1002/cne.10447

Qiao, L. Y., and Vizzard, M. A. (2005). Spinal cord injury-induced expression of TrkA, TrkB, phosphorylated CREB, and c-Jun in rat lumbosacral dorsal root ganglia. J. Comp. Neurol. 482, 142-154. doi: 10.1002/cne.20394

Quillin, R. B., and Erickson, D. R. (2012). Management of interstitial cystitis/bladder pain syndrome: a urology perspective. Urol. Clin. North Am. 39, 389-396. doi: 10.1016/j.ucl.2012.05.007

Ressler, K. J., and Mayberg, H. S. (2007). Targeting abnormal neural circuits in mood and anxiety disorders: from the laboratory to the clinic. Nat. Neurosci. 10, 1116-1124. doi: 10.1038/nn1944

Ressler, K. J., Mercer, K. B., Bradley, B., Jovanovic, T., Mahan, A., Kerley, K., et al. (2011). Post-traumatic stress disorder is associated with PACAP and the PAC1 receptor. Nature 470, 492-497. doi: 10.1038/nature09856

Robbins, M., DeBerry, J., and Ness, T. (2007). Chronic psychological stress enhances nociceptive processing in the urinary bladder in high-anxiety rats. Physiol. Behav. 91, 544-550. doi: 10.1016/j.physbeh.2007.04.009

Robbins, M. T., and Ness, T. J. (2008). Footshock-induced urinary bladder hypersensitivity: role of spinal corticotropin-releasing factor receptors. J. Pain 9, 991-998. doi: 10.1016/j.jpain.2008.05.006

Roman, C. W., Lezak, K. R., Hartsock, M. J., Falls, W. A., Braas, K. M., Howard, A. B., et al. (2014). PAC1 receptor antagonism in the bed nucleus of the stria terminalis (BNST) attenuates the endocrine and behavioral consequences of chronic stress. Psychoneuroendocrinology 47, 151-165. doi: 10.1016/j.psyneuen. 2014.05.014

Rothrock, N. E., Lutgendorf, S. K., Kreder, K. J., Ratliff, T., and Zimmerman, B. (2001a). Stress and symptoms in patients with interstitial cystitis: a life stress model. Urology 57, 422-427. doi: 10.1016/S0090-4295(00)00988-2

Rothrock, N. E., Lutgendorf, S. K., Kreder, K. J., Ratliff, T. L., and Zimmerman, B. (2001b). Daily stress and symptom exacerbation in interstitial cystitis patients. Urology 57(6 Suppl. 1), 122. doi: 10.1016/S0090-4295(01)01075-5

Rouzade-Dominguez, M. L., Pernar, L., Beck, S., and Valentino, R. J. (2003). Convergent responses of Barrington's nucleus neurons to pelvic visceral stimuli in the rat: a juxtacellular labelling study. Eur. J. Neurosci. 18, 3325-3334. doi: 10.1111/j.1460-9568.2003.03072.x

Saban, R. (2015). Angiogenic factors, bladder neuroplasticity and interstitial cystitis-new pathobiological insights. Transl. Androl. Urol. 4, 555-562. doi: 10.3978/j.issn.2223-4683.2015.08.05

Sant, G. R., and Hanno, P. M. (2001). Interstitial cystitis: current issues and controversies in diagnosis. Urology 57(6 Suppl. 1), 82-88. doi: 10.1016/S00904295(01)01131-1

Schnegelsberg, B., Sun, T. T., Cain, G., Bhattacharya, A., Nunn, P. A., Ford, A. P., et al. (2010). Overexpression of NGF in mouse urothelium leads to neuronal hyperinnervation, pelvic sensitivity, and changes in urinary bladder function. Am. J. Physiol. Regul. Integr. Comp. Physiol. 298, R534-R547. doi: 10.1152/ ajpregu.00367.2009

Shiotani, Y., Kimura, S., Ohshige, Y., Yanaihara, C., and Yanaihara, N. (1995). Immunohistochemical localization of pituitary adenylate cyclase-activating polypeptide (PACAP) in the adrenal medulla of the rat. Peptides 16, 1045-1050. doi: 10.1016/0196-9781(95)00076-V
Skryma, R., Prevarskaya, N., Gkika, D., and Shuba, Y. (2011). From urgency to frequency: facts and controversies of TRPs in the lower urinary tract. Nat. Rev. Urol. 8, 617-630. doi: 10.1038/nrurol.2011.142

Smith, A. L., Leung, J., Kun, S., Zhang, R., Karagiannides, I., Raz, S., et al. (2011). The effects of acute and chronic psychological stress on bladder function in a rodent model. Urology 78, 967.e1-7. doi: 10.1016/j.urology.2011. 06.041

Spanos, C., Pang, X., Ligris, K., Letourneau, R., Alferes, L., Alexacos, N., et al. (1997). Stress-induced bladder mast cell activation: implications for interstitial cystitis. J. Urol. 157, 669-672. doi: 10.1016/S0022-5347(01)65247-9

Spengler, D., Waeber, C., Pantaloni, C., Holsboer, F., Bockaert, J., Seeburg, P. H., et al. (1993). Differential signal transduction by five splice variants of the PACAP receptor. Nature 365, 170-175. doi: 10.1038/365170a0

Steers, W. D., Ciambotti, J., Etzel, B., Erdman, S., and de Groat, W. C. (1991). Alterations in afferent pathways from the urinary bladder of the rat in response to partial urethral obstruction. J. Comp. Neurol. 310, 401-410. doi: 10.1002/cne. 903100309

Stephens, M. A., Mahon, P. B., McCaul, M. E., and Wand, G. S. (2016). Hypothalamic-pituitary-adrenal axis response to acute psychosocial stress: Effects of biological sex and circulating sex hormones. Psychoneuroendocrinology 66, 47-55. doi: 10.1016/j.psyneuen.2015.12.021

Studeny, S., Cheppudira, B. P., Meyers, S., Balestreire, E. M., Apodaca, G., Birder, L. A., et al. (2008). Urinary bladder function and somatic sensitivity in vasoactive intestinal polypeptide (VIP) -/- mice. J. Mol. Neurosci. 36, 175-187. doi: $10.1007 / \mathrm{s} 12031-008-9100-8$

Sundler, F., Ekblad, E., Hannibal, J., Moller, K., Zhang, Y. Z., Mulder, H., et al. (1996). Pituitary adenylate cyclase-activating peptide in sensory and autonomic ganglia: localization and regulation. Ann. N. Y. Acad. Sci. 805, 410-426; discussion 427-418. doi: 10.1111/j.1749-6632.1996.tb17501.x

Tank, P. W. (2009). Grant's Dissector. Philadelphia, PA: Lippincott Williams \& Wilkins.

Tatsuno, I., Somogyvari-Vigh, A., and Arimura, A. (1994). Developmental changes of pituitary adenylate cyclase activating polypeptide (PACAP) and its receptor in the rat brain. Peptides 15, 55-60. doi: 10.1016/0196-9781(94)90170-8

Turner-Cobb, J. M. (2005). Psychological and stress hormone correlates in early life: a key to HPA-axis dysregulation and normalisation. Stress 8, 47-57. doi: 10.1080/10253890500095200

Valentino, R. J. (1988). CRH effects on central noradrenergic neurons: relationship to stress. Adv. Exp. Med. Biol. 245, 47-64. doi: 10.1007/978-1-4899-2064-5_5

Vaughan, C. W., and Satchell, P. M. (1992). Role of sympathetic innervation in the feline continence process under natural filling conditions. J. Neurophysiol. 68, 1842-1849.

Vizzard, M. A. (2000a). Alterations in spinal cord Fos protein expression induced by bladder stimulation following cystitis. Am. J. Physiol. Regul. Integr. Comp. Physiol. 278, R1027-R1039.

Vizzard, M. A. (2000b). Changes in urinary bladder neurotrophic factor mRNA and NGF protein following urinary bladder dysfunction. Exp. Neurol. 161, 273-284. doi: 10.1006/exnr.1999.7254

Vizzard, M. A. (2000c). Up-regulation of pituitary adenylate cyclase-activating polypeptide in urinary bladder pathways after chronic cystitis. J. Comp. Neurol. 420, 335-348. doi: 10.1002/(SICI)1096-9861(20000508)420:3<335:: AID-CNE5>3.0.CO;2-\#

Vizzard, M. A. (2001). Alterations in neuropeptide expression in lumbosacral bladder pathways following chronic cystitis. J. Chem. Neuroanat. 21, 125-138. doi: 10.1016/S0891-0618(00)00115-0

Vizzard, M. A. (2006). Neurochemical plasticity and the role of neurotrophic factors in bladder reflex pathways after spinal cord injury. Prog. Brain Res. 152, 97-115. doi: 10.1016/S0079-6123(05)52007-7

Wang, E. C., Lee, J. M., Ruiz, W. G., Balestreire, E. M., von Bodungen, M., Barrick, S., et al. (2005). ATP and purinergic receptor-dependent membrane traffic in bladder umbrella cells. J. Clin. Invest. 115, 2412-2422. doi: 10.1172/ JCI24086

Wantuch, C., Piesla, M., and Leventhal, L. (2007). Pharmacological validation of a model of cystitis pain in the mouse. Neurosci. Lett. 421, 250-252. doi: 10.1016/j.neulet.2007.05.043

Westropp, J. L., and Buffington, C. A. (2002). In vivo models of interstitial cystitis. J. Urol. 167(2 Pt 1), 694-702. doi: 10.1097/00005392-20020200000068 
Wood, S. K., Baez, M. A., Bhatnagar, S., and Valentino, R. J. (2009). Social stressinduced bladder dysfunction: potential role of corticotropin-releasing factor. Am. J. Physiol. Regul. Integr. Comp. Physiol. 296, R1671-R1678. doi: 10.1152/ ajpregu.91013.2008

Woolf, C. J., Allchorne, A., Safieh-Garabedian, B., and Poole, S. (1997). Cytokines, nerve growth factor and inflammatory hyperalgesia: the contribution of tumour necrosis factor alpha. Br. J. Pharmacol. 121, 417-424. doi: 10.1038/sj.bjp. 0701148

Wright, D. E., and Snider, W. D. (1995). Neurotrophin receptor mRNA expression defines distinct populations of neurons in rat dorsal root ganglia. J. Comp. Neurol. 351, 329-338. doi: 10.1002/cne.903510302

Yamamoto, K., Takao, T., Nakayama, J., Kiuchi, H., Okuda, H., Fukuhara, S., et al. (2012). Water avoidance stress induces frequency through cyclooxygenase-2 expression: a bladder rat model. Int. J. Urol. 19, 155-162. doi: 10.1111/j.14422042.2011.02905.x

Yoshimura, N., Bennett, N. E., Hayashi, Y., Ogawa, T., Nishizawa, O., Chancellor, M. B., et al. (2006). Bladder overactivity and hyperexcitability of bladder afferent neurons after intrathecal delivery of nerve growth factor in rats. J. Neurosci. 26, 10847-10855. doi: 10.1523/JNEUROSCI.3023-06.2006

Yoshimura, N., Kaiho, Y., Miyazato, M., Yunoki, T., Tai, C., Chancellor, M. B., et al. (2008). Therapeutic receptor targets for lower urinary tract dysfunction. Naunyn Schmiedebergs Arch. Pharmacol. 377, 437-448. doi: 10.1007/s00210007-0209-z

Yoshimura, N., Seki, S., Chancellor, M. B., de Groat, W. C., and Ueda, T. (2002). Targeting afferent hyperexcitability for therapy of the painful bladder syndrome. Urology 59(5 Suppl. 1), 61-67. doi: 10.1016/S0090-4295(01) 01639-9
Zeidel, M. L. (1996). Low permeabilities of apical membranes of barrier epithelia: what makes watertight membranes watertight? Am. J. Physiol. 271(2 Pt 2), F243-F245.

Zhang, Q., Shi, T. J., Ji, R. R., Zhang, Y. Z., Sundler, F., Hannibal, J., et al. (1995). Expression of pituitary adenylate cyclase-activating polypeptide in dorsal root ganglia following axotomy: time course and coexistence. Brain Res. 705, 149-158. doi: 10.1016/0006-8993(95)01150-1

Zhang, Y. Z., Hannibal, J., Zhao, Q., Moller, K., Danielsen, N., Fahrenkrug, J., et al. (1996). Pituitary adenylate cyclase activating peptide expression in the rat dorsal root ganglia: up-regulation after peripheral nerve injury. Neuroscience 74, 1099-1110. doi: 10.1016/0306-4522(96) 00168-6

Zvara, P., and Vizzard, M. A. (2007). Exogenous overexpression of nerve growth factor in the urinary bladder produces bladder overactivity and altered micturition circuitry in the lumbosacral spinal cord. BMC Physiol. 7:9. doi: $10.1186 / 1472-6793-7-9$

Conflict of Interest Statement: The authors declare that the research was conducted in the absence of any commercial or financial relationships that could be construed as a potential conflict of interest.

Copyright (c) 2017 Girard, Tooke and Vizzard. This is an open-access article distributed under the terms of the Creative Commons Attribution License (CC BY). The use, distribution or reproduction in other forums is permitted, provided the original author(s) or licensor are credited and that the original publication in this journal is cited, in accordance with accepted academic practice. No use, distribution or reproduction is permitted which does not comply with these terms. 